\title{
Murine Osteoblastic and Osteoclastic Differentiation on Strontium Releasing Hydroxyapatite Forming Cements
}

Satish S. Singh ${ }^{\mathrm{a}}$, Abhijit Roy ${ }^{\mathrm{b}}$, Boeun E. Lee ${ }^{\mathrm{b}}$, Shrey Parekh $^{\mathrm{b}}$, and Prashant N. Kumta ${ }^{\mathrm{a}, \mathrm{b}, \mathrm{c}, \mathrm{d}, \mathrm{e}}$

${ }^{a}$ Department of Chemical \& Petroleum Engineering, University of Pittsburgh, Pittsburgh, PA, 15261, USA. sss42@pitt.edu,

${ }^{\mathrm{b}}$ Department of Bioengineering, University of Pittsburgh, Pittsburgh, PA, 15261, USA. abr20@pitt.edu, bol11@pitt.edu,smp116@pitt.edu

${ }^{\mathrm{c}}$ Center for Craniofacial Regeneration, University of Pittsburgh, Pittsburgh, PA, 15261, U.S.A.

${ }^{\mathrm{d}}$ Department of Mechanical Engineering and Materials Science, University of Pittsburgh, PA, 15261, U.S.A.

${ }^{\mathrm{e}}$ Center for Complex Engineered Multifunctional Materials, University of Pittsburgh, PA, 15261, U.S.A.pkumta@pitt.edu.

Abstract: Ionic substitutions in hydroxyapatite (HA) scaffolds and self-setting cements containing $\mathrm{Sr}^{2+}$ ions incorporated are particularly of interest in bone regeneration. To date, the approach widely used to incorporate $\mathrm{Sr}^{2+}$ ions into $\mathrm{HA}$ cements has been the addition of $\mathrm{Sr}^{2+}$ containing salts, such as $\mathrm{SrCO}_{3}, \mathrm{SrCl}_{2} \bullet 6 \mathrm{H}_{2} \mathrm{O}$, or $\mathrm{SrHPO}_{4}$. However, this approach is dependent upon the relative solubility of $\mathrm{Sr}^{2+}$ containing salts with respect to calcium phosphate $(\mathrm{CaP})$ precursors. Therefore, in the current study $\mathrm{Sr}^{2+}$ substituted dicalcium phosphate dihydrate (DCPD) was first synthesized and directly reacted with tetracalcium phosphate (TTCP) to form $\mathrm{Sr}^{2+}$ substituted HA forming cements. Rietveld refinement indicated that after one week of aging in phosphate buffered saline, cements prepared with and without $\mathrm{Sr}^{2+}$ were composed of $75 \%$ HA and $25 \%$ unreacted TTCP by weight. Cements prepared with $10 \% \mathrm{Sr}^{2+}$ DCPD exhibited increased compressive strengths in comparison to unsubstituted cements. Increased MC3T3-E1 
proliferation and differentiation were also observed on the cements prepared with increasing $\mathrm{Sr}^{2+}$ content. It was concluded that both the scaffold microstructure and $\mathrm{Sr}^{2+}$ ion release supported osteogenic differentiation. With respect to osteoclastic differentiation, no statistically significant differences in TRAP activity or cell morphology were observed. This suggests that the amount of $\mathrm{Sr}^{2+}$ released may have been too low to influence osteoclast formation in comparison to unsubstituted cements. The results obtained herein demonstrate that the use of $\mathrm{Sr}^{2+}$ substituted DCPD precursors rather than individually separate $\mathrm{Sr}^{2+}$ containing salts may be a useful approach to prepare $\mathrm{Sr}^{2+}$ containing HA cements.

\section{Keywords: Hydroxyapatite, Strontium, Osteoblast, Osteoclast, Differentiation}

\section{Introduction}

$\mathrm{Sr}^{2+}$ substituted calcium phosphates (CaPs) have shown promise in the development of synthetic bone graft substitutes $[1,2]$. This is primarily due to the capability of $\mathrm{Sr}^{2+}$ ions to stimulate the differentiation of osteoblast progenitor cells, limit osteoclastic resorption, and enhance the radiopacity of CaPs [3]. To improve the clinical application of $\mathrm{Sr}^{2+}$ substituted $\mathrm{CaP}$ based scaffolds, self-setting $\mathrm{Sr}^{2+}$ substituted hydroxyapatite (HA) and dicalcium phosphate dihydrate (DCPD) forming cements have been developed [4]. HA forming CaP cements are traditionally of greater interest due to their less acidic setting reaction and improved mechanical properties. They have also been prepared using a wide range of $\mathrm{CaP}$ precursors. However, they are most commonly prepared either by the hydrolysis of $\alpha$-tricalcium phosphate $(\alpha$-TCP) or by an acidbase reaction between tetracalcium phosphate (TTCP) and either dicalcium phosphate anhydrous (DCPA) or DCPD [5, 6]. 
To date, the majority of work reported on $\mathrm{Sr}^{2+}$ substituted HA forming cements has been with formulations prepared using $\alpha$-TCP rather than TTCP and either DCPA or DCPD. Schumacher et. al for instance prepared $\mathrm{Sr}^{2+}$ releasing HA forming cements using $\alpha$-TCP and DCPA with mixtures of $\mathrm{CaCO}_{3}$ and $\mathrm{SrCO}_{3}$ forming either $\mathrm{Sr}^{2+}$ substituted $\mathrm{HA}$ or clusters of $\mathrm{SrCO}_{3}$ within a HA matrix [7, 8]. The capability of these cements to support the proliferation and differentiation of human mesenchymal stem cells was also demonstrated. $\mathrm{SrCl}_{2} \bullet 6 \mathrm{H}_{2} \mathrm{O}$ has also been used to introduce $\mathrm{Sr}^{2+}$ ions to HA forming cements prepared using $\alpha$-TCP $[9,10]$. In both cases, the incorporation of $\mathrm{Sr}^{2+}$ into the HA crystal structure, which is necessary for the sustained release of $\mathrm{Sr}^{2+}$ ions, is dependent upon the relative solubility of the $\mathrm{Sr}^{2+}$ containing precursors with respect to $\alpha$-TCP and the participation of $\mathrm{Sr}^{2+}$ in the re-precipitation process. Therefore, the synthesis of $\mathrm{Sr}^{2+}$ containing $\mathrm{CaP}$ precursors and their direct use in the cement forming setting reaction to form the HA cements, may be a more efficient and prudent route to incorporate $\mathrm{Sr}^{2+}$ ions into the resultant HA crystal structure during the cement setting reaction rather than using $\mathrm{Sr}^{2+}$ containing salts. This approach has previously been explored using $\mathrm{Sr}^{2+}$ substituted $\alpha$-TCP [11].

In one of the few reports where $\mathrm{Sr}^{2+}$ substituted HA forming cements were prepared using TTCP and either DCPA or DCPD rather than $\alpha$-TCP, Guo et. al prepared $\mathrm{SrHPO}_{4}$ (DSP) by precipitation and studied the cements formed using ternary mixtures of TTCP, DCPA, and DSP [4]. As a result of the varying solubility and particle sizes of DSP and DCPA, unreacted DSP was detected in the cements formed after up to one week in $100 \%$ humidity conditions. Despite this, further work studying these cements indicated improved in vitro cytocompatibility and in vivo degradation when implanted intramuscularly and in a femoral defect in rabbits with increasing $\mathrm{Sr}^{2+}$ content [12]. However, the incorporation of $\mathrm{Sr}^{2+}$ ions into the HA crystal 
structure is once again dependent upon the relative solubility of the two acidic precursors namely, DCPA and DSP.

Therefore, in the current study $\mathrm{Sr}^{2+}$ substituted DCPD (SrDCPD) of varying levels of substitution were directly prepared for the first time to the best of what is reported in the literature by a simple precipitation route under aqueous conditions and reacted with TTCP to form $\mathrm{Sr}^{2+}$ substituted HA (SrHA) forming cements. It was further hypothesized that the use of $\mathrm{Sr}$ substituted DCPD, SrDCPD would lead to the incorporation of $\mathrm{Sr}^{2+}$ into the HA formed during the cement setting reaction in a very controlled manner during the acid-base reaction between TTCP and DCPD rather than involving a competing reaction of the two CaP precursors with a $\mathrm{Sr}$ containing salt as reported in the literature. The influence of varying the $\mathrm{Sr}^{2+}$ content in the cement scaffolds generated by this simple chemical reaction approach involving substituted precursors on the setting kinetics, phase composition, and compressive strength was

characterized. In addition, the capability of $\mathrm{Sr}^{2+}$ containing cements to support the in vitro osteoblastic and osteoclastic differentiation of mouse preosteoblasts as well as monocytes was also studied and reported herein.

\section{Materials and Methods}

\subsection{DCPD Precipitation}

All the reagents used for the synthesis were acquired from Sigma-Aldrich and used in the form in which they were received. DCPD was precipitated under aqueous conditions using a method previously described [13]. $\mathrm{CaCl}_{2} \cdot 2 \mathrm{H}_{2} \mathrm{O}$ and $\mathrm{SrCl}_{2} \cdot 6 \mathrm{H}_{2} \mathrm{O}$ mixtures (Table 1) were dissolved in $100 \mathrm{~mL}$ of deionized water. This solution was added dropwise to $100 \mathrm{~mL}$ of a $0.5 \mathrm{M} \mathrm{Na}_{2} \mathrm{HPO}_{4}$ solution under constant stirring at room temperature. The precipitate formed was collected ten 
minutes after combining the solutions allowing the reaction illustrated in equation (1) to proceed to completion. The precipitate formed was subsequently centrifuged and washed using DI water. The final washing step was performed with ethanol and the precipitate was dried at room temperature under vacuum to avoid the formation of DCPA.

$$
\text { (1) }(1-\mathrm{a}) \mathrm{CaCl}_{2}+\mathrm{aSrCl}_{2}+\mathrm{Na}_{2} \mathrm{HPO}_{4} \rightarrow \mathrm{Ca}_{(1-\mathrm{a})} \mathrm{Sr}_{\mathrm{a}} \mathrm{HPO}_{4} \cdot 2 \mathrm{H}_{2} \mathrm{O}+2 \mathrm{NaCl}
$$

\subsection{Powder Characterization}

The phase composition of the powders formed after precipitation was determined using X-ray diffraction. Accordingly, X-ray diffraction patterns were collected using a Philips X-Pert PRO diffractometer employing $\mathrm{Cu} \mathrm{K} \alpha$ radiation $(\lambda=1.5406 \AA$ ) ) with a Si-detector (X'celerator). The Xray generator was operated at $45 \mathrm{kV}$ and $40 \mathrm{~mA}$ at a $2 \theta$ range of $10-70^{\circ}$ with a step size of $0.0167^{\circ}$ and a time per step of $3 \mathrm{~s}$. Elemental analysis of the precipitated powders was performed using inductively coupled plasma optical emission spectrometry (ICP-OES, iCAP duo 6500, Thermo Scientific). Briefly, $10 \mathrm{mg}$ of powder samples were dissolved in $3.5 \% \mathrm{HNO}_{3}$. These solutions were further diluted and analyzed using ICP-OES employing known standards for $\mathrm{Ca}^{2+}, \mathrm{Sr}^{2+}$, and $\mathrm{PO}_{4}{ }^{3-}$. Standard solutions have been prepared using the $3.5 \% \mathrm{HNO}_{3}$ stock solution. Scanning electron microscopy (SEM, Philips XL30 FEG ESEM) was used to analyze the particle size and microstructure of the powders formed after precipitation. Samples were sputter coated with palladium (Cressington, 108) prior to SEM analysis.

\subsection{Cement Characterization}

Powder mixtures of $45 \%$ DCPD containing varying amounts of Sr substitution and 55\% TTCP (<53 $\mu \mathrm{m}$, HIMED, Old Bethpage, NY), by weight, were prepared using a mortar and pestle. The cement pastes were formed by combining TTCP-DCPD powder mixtures with either DI water or 
a $1.25 \% \mathrm{Na}_{2} \mathrm{HPO}_{4}$ solution using a powder to liquid ratio of $2.2 \mathrm{~g} \mathrm{~mL}^{-1}$. The resulting pastes were filled into $10 \mathrm{~mm}$ diameter cylindrical molds and allowed to fully set at $37^{\circ} \mathrm{C}$. The cement reaction between TTCP and DCPD resulting in the formation of HA is illustrated by equation (2).

$$
\text { (2) } \mathrm{Ca}_{4}\left(\mathrm{PO}_{4}\right)_{2} \mathrm{O}+\mathrm{CaHPO}_{4} \cdot 2 \mathrm{H}_{2} \mathrm{O} \rightarrow \mathrm{Ca}_{5}\left(\mathrm{PO}_{4}\right)_{3} \mathrm{OH}+2 \mathrm{H}_{2} \mathrm{O}
$$

The initial and final setting times were determined using a Gillmore Needle Apparatus (ASTM C-266). After complete setting, the cements were immersed in phosphate buffered saline (PBS, Lonza, Allendale, $\mathrm{NJ}$ ) and incubated at $37^{\circ} \mathrm{C}$ for up to one week. At various time points during the one week period, samples were collected and analyzed using X-ray diffraction. Rietveld refinement was used to quantitatively analyze the phase composition (HighScore Plus, Version 3.0e) using the ICSD reference patterns for HA (22060), DCPD (16132), and TTCP (2631). The wet compressive strengths of the cement scaffolds after immersion in PBS was analyzed using a $2 \mathrm{kN}$ load cell (Instron, Norwood, MA) and a cross head speed of $1.3 \mathrm{~mm} \mathrm{~min}^{-1}$. A minimum of six repeats were performed for each condition at each time point using $6 \mathrm{~mm}$ diameter cylindrical scaffolds which were $12 \mathrm{~mm}$ long. The $\%$ porosity of the cement scaffolds after immersion in PBS was determined using the formula illustrated in equation (3).

$$
\text { (3) } \% \text { porosity }=1-\rho_{\mathrm{A}} / \rho_{\mathrm{T}}
$$

The true density $\left(\rho_{\mathrm{T}}\right)$ was determined using helium pycnomtery (AccuPyc II 1340, Micromeritics, Norcross, GA) and the apparent density $\left(\rho_{\mathrm{A}}\right)$ was determined using an envelope density analyzer (GeoPyc, Micromeritics, Norcross, GA). A minimum of four independent repeats were accordingly analyzed for each condition.

\subsection{Cell Culture}




\subsubsection{MC3T3-E1 Cell Culture}

MC3T3-E1 murine preosteoblast cell line was obtained from ATCC (Manassas, VA). Cells were cultured at $37^{\circ} \mathrm{C}$ in $5 \% \mathrm{CO}_{2}$ and $95 \%$ relative humidity in minimum essential medium alpha (MEM $\alpha$, Gibco, Grand Island, NY) containing 10\% fetal bovine serum (FBS, Atlanta Biologicals, Lawrenceville, GA) and 1\% penicillin streptomycin (P/S, Gibco, Grand Island, NY). During direct culture experiments, cells were seeded at a density of 50,000 cells per well directly on cement scaffolds. For indirect culture, cells were seeded on tissue culture plastic and the cement scaffolds were placed on transwell permeable supports with a pore size of $0.4 \mu \mathrm{m}$ and a nominal pore density of $4 * 10^{6}$ pores $\mathrm{cm}^{-2}$ (Corning, Tewksbury, MA). In both cases, the samples were sterilized using ethanol and ultraviolet light. Osteogenic differentiation was induced by culturing in growth media supplemented with $0.05 \mathrm{mM}$ ascorbic acid, $10 \mathrm{mM} \beta$ glycerophosphate, and $100 \mathrm{nM}$ dexamethasone.

\subsubsection{RAW264.7 Cell Culture}

RAW264.7 murine monocyte cell line was also obtained from ATCC. The cells were cultured in Dulbecco's Minimum Essential Medium (DMEM, ATCC, Manassas, VA) supplemented with $10 \% \mathrm{FBS}$ and $1 \% \mathrm{P} / \mathrm{S}$ at $37^{\circ} \mathrm{C}$ in $5 \% \mathrm{CO}_{2}$ and $95 \%$ relative humidity. Cells were seeded directly on cement scaffolds at a density of 10,000 cells per well. After 1 day of culture, the culture media was supplemented with $50 \mathrm{ng} \mathrm{mL}^{-1}$ of receptor activator of nuclear factor kappa-B ligand (RANKL, BioLegend, San Diego, CA) and was refreshed daily for the duration of the experiment.

\subsection{MC3T3-E1 Proliferation}


The alamarblue cell viability assay (Invitrogen, Grand Island, NY) was used to evaluate MC3T3E1 proliferation on all the cements prepared with varying elemental compositions. At the specific time points of interest, the growth media was replaced by $1 \mathrm{~mL}$ of alamarblue diluted in growth media, according to the manufacturer's protocol. Samples were then incubated with the alamarblue reagent for 6 hours. $50 \mu \mathrm{L}$ aliquots of media were collected at the end of the incubation period and fluorescence was measured at an excitation wavelength of $540 \mathrm{~nm}$ and an emission wavelength of $590 \mathrm{~nm}$. Cement scaffolds without the cells were used as negative controls to ensure that the release of $\mathrm{Ca}^{2+}, \mathrm{Sr}^{2+}$, and $\mathrm{PO}_{4}{ }^{3-}$ ions into the surrounding culture media did not influence the reduction of alamarblue. The concentration of $\mathrm{Ca}^{2+}, \mathrm{Sr}^{2+}$, and $\mathrm{PO}_{4}{ }^{3-}$ leached into the culture media during the viability experiment was determined using ICP-OES, as outlined above and also previously described. Briefly, the culture media samples were collected every other day and diluted in $\mathrm{pH} 7.4$ tris buffer for analysis with ICP-OES using the known standards.

\subsection{Alkaline Phosphatase (ALP) Activity}

MC3T3-E1 cells were lysed using a commercially available lysis buffer according to the manufacturer's protocol (CelLytic M, Sigma Aldrich). $170 \mu \mathrm{L}$ of $1 \mathrm{~g} \mathrm{~L}^{-1}$ p-nitrophenyl phosphate (pNPP) dissolved in $0.2 \mathrm{M}$ tris buffer (SIGMAFAST ${ }^{\mathrm{TM}}$ p-Nitrophenyl phosphate tablets, Sigma Aldrich) was added to $30 \mu \mathrm{L}$ of the cell lysate. Samples were incubated at $37^{\circ} \mathrm{C}$ for one hour prior to stopping the reaction by adding $20 \mu \mathrm{L}$ of $0.3 \mathrm{M} \mathrm{NaOH}$. The concentration of pnitrophenyl in solution after 1 hour of incubation was then determined by measuring the absorbance at $405 \mathrm{~nm}$. The ALP activity was normalized with respect to the total protein concentration in the collected cell lysate. 


\subsection{Osteogenic Protein Expression}

The intracellular expression of osteoprotegerin (OPG) and osteocalcin (OCN) of MC3T3-E1 cells cultured on the CaP cements was quantified using a MAGPIX instrument (Luminex, Austin, TX). Cell lysates were accordingly incubated overnight at $4^{\circ} \mathrm{C}$ with antibody conjugated magnetic beads (EMD Millipore, Billerica, MA) according to the manufacturer's protocol. After incubation, the well contents were washed and exposed to a biotinylated detection antibody followed by streptavidin-phycoerythrin to complete the surface reaction. Protein concentrations were then determined by using known standards. Measurements were conducted in triplicate for each sample and were normalized with respect to the total protein concentration.

\subsection{Tartarate Resistant Acidic Phosphatase (TRAP) Activity}

Cell lysates were collected as previously described in the earlier section. $100 \mu \mathrm{L}$ of RAW264.7 cell lysate, collected after 5 and 10 days of culture on the cement scaffolds in the presence of RANKL, was added to $50 \mu \mathrm{L}$ of $5 \mathrm{mM}$ pNPP in $25 \mathrm{mM}$ sodium acetate/20 mM sodium tartarate at $\mathrm{pH}$ 4.9. The samples were incubated at $37^{\circ} \mathrm{C}$ for thirty minutes prior to stopping the reaction by adding $200 \mu \mathrm{L}$ of $0.5 \mathrm{M} \mathrm{NaOH}$. The concentration of p-nitrophenyl in solution after 1 hour of incubation was then determined by measuring absorbance at $405 \mathrm{~nm}$.

\subsection{RAW264.7 Morphology}

After 10 days of culture on the cements with varying $\mathrm{Sr}^{2+}$ content in the presence of RANKL, RAW264.7 cells were fixed using 4\% paraformaldehyde and washed with PBS. Prior to staining, the cell membranes were permeabilized using $0.1 \%$ Triton-X diluted in PBS for ten minutes. Actin staining was performed by incubating the samples in phalloidin (Phalloidin tetramethylrhodamine B isothiocyanate, Sigma Aldrich) diluted in PBS for forty minutes. DAPI 
(4',6-Diamidino-2-phenylindole dihydrochloride, Sigma Aldrich) was similarly diluted in PBS and used to stain the cell nuclei according to the manufacturer's protocol. Samples were then imaged using a fluorescent microscope (Olympus CXK41).

\subsection{Statistical Analysis}

A one way analysis of variance (ANOVA) was used to determine the statistical significance. The mean and standard deviation were then reported. The Tukey-Kramer test was used for all the pairwise comparisons and a p value $<0.05$ was considered significant.

\section{Results and Discussion}

\subsection{DCPD Characterization}

X-ray diffraction was used to study the phase composition and crystallinity of the powders formed by precipitation at room temperature after drying under vacuum (Figure 1). For all the compositions considered and indicated in Table 1, DCPD (JCPDS 09-0077) was the only crystalline phase detected. The increased intensity of the peak near $12^{\circ} 2 \theta$ for all of the synthesized conditions in comparison to the reference spectra is indicative of a preferred orientation along the (020) direction. A similar preferred orientation has previously been reported when DCPD was precipitated under aqueous conditions [13, 14]. Based on these results, it can be concluded that up to $10 \mathrm{~mol}$. $\% \mathrm{Sr}^{2+}$ substituted DCPD was prepared using this synthesis approach.

Elemental analysis of the precipitated Sr containing DCPD powders was performed by ICP-OES to more accurately determine the amount of $\mathrm{Sr}^{2+}$ incorporated into the DCPD crystal lattice. Powder samples were dissolved in dilute acidic solutions and analyzed using ICP-OES with known standards for $\mathrm{Ca}^{2+}, \mathrm{Sr}^{2+}$, and $\mathrm{PO}_{4}{ }^{3-}$. Four batches for each condition were analyzed 
independently (Table 2). As expected, $\mathrm{Sr}^{2+}$ was not detected in unsubstituted DCPD. However, 4.30 and $8.84 \% \mathrm{Sr} /(\mathrm{Ca}+\mathrm{Sr})$ values were obtained for samples precipitated with 5 and $10 \%$ $\mathrm{Sr} /(\mathrm{Ca}+\mathrm{Sr})$, respectively. In all the cases, the measured $(\mathrm{Ca}+\mathrm{Sr}) / \mathrm{P}$ ratio was also close to 1 matching that of DCPD, further confirming the formation of single phase DCPD.

Due to the similar ionic radii of $\mathrm{Sr}^{2+}(0.12 \mathrm{~nm})$ with $\mathrm{Ca}^{2+}(0.099 \mathrm{~nm})$, a relatively high retention of $\mathrm{Sr}^{2+}$ in various $\mathrm{CaP}$ phases has been reported in comparison to other elements $[15,16]$. Despite the fact that $\mathrm{Sr}^{2+}$ can occupy all of the $\mathrm{Ca}^{2+}$ sites in the DCPD crystal lattice, the majority of work reported on the ionic substitution of $\mathrm{Sr}^{2+}$ in $\mathrm{CaPs}$ has focused on HA [17]. The influence of $\mathrm{Sr}^{2+}$ substitution on the microstructure of DCPD particles was also analyzed since the reactant particle size and shape are known to influence the cement properties (Figure 2). For undoped, unsubstituted DCPD, the characteristic broad plate like morphology of DCPD was observed (Figure 2a)) [18]. The particles imaged as shown in the SEM image in Figure 2a were approximately $10-15 \mu \mathrm{m}$ in width. A similar morphology was also observed for DCPD prepared with both 5 and $10 \% \mathrm{Sr}$ (Figure 2 b) and c)). However, a slight reduction in the size was observed for DCPD particles prepared with 10\% $\mathrm{Sr}$ in comparison to those precipitated either without $\mathrm{Sr}$ or with $5 \% \mathrm{Sr}$.

\subsection{Cement Characterization}

\subsubsection{Setting Time}

Single phase DCPD with varying levels of $\mathrm{Sr}^{2+}$ substitution as outlined in the experimental section were combined with commercially available TTCP powder in a 45:55 DCPD:TTCP ratio of mixtures by weight. The powder mixtures were thoroughly mixed using a mortar and combined with either DI water or a 1.25 wt. $\% \mathrm{Na}_{2} \mathrm{HPO}_{4}$ solution using a P/L ratio of $2.2 \mathrm{~g} \mathrm{~mL}^{-1}$. 
The resulting pastes were then allowed to fully set at $37^{\circ} \mathrm{C}$ during which the initial and final setting times were determined using a Gillmore Needle Apparatus (Table 3). Cements prepared using undoped or unsubstituted DCPD set after approximately 26 minutes when using water as the liquid component. The final setting time for the undoped or unsubstituted cements reduced to 6 minutes when using $1.25 \% \mathrm{Na}_{2} \mathrm{HPO}_{4}$. Setting times with both water and $\mathrm{Na}_{2} \mathrm{HPO}_{4}$ increased in comparison to undoped and unsubstituted cements when using either 5 or $10 \%$ Sr substitutions in the DCPD, namely 5\%SrDCPD and 10\%SrDCPD. A similar decrease in setting time was also observed when using $\mathrm{Na}_{2} \mathrm{HPO}_{4}$ rather than water for both $\mathrm{Sr}^{2+}$ containing cement compositions.

The TTCP-DCPD setting reaction is initiated by the dissolution of DCPD particles [19]. Therefore, the use of $\mathrm{Na}_{2} \mathrm{HPO}_{4}$ rather than water accelerates the cement setting reaction and correspondingly, the time due to the enhanced solubility of DCPD under slightly basic conditions and thus provides the increased $\mathrm{PO}_{4}{ }^{3-}$ concentration necessary to support the formation of apatite $[20,21]$. In studying the TTCP-DCPA cement setting reaction, Greish et. al concluded that DCPA was first completely consumed while TTCP was only partially consumed, resulting in the formation of calcium deficient HA (CDHA) [22]. Correspondingly, further consumption of TTCP and increase in $\mathrm{pH}$ then resulted in the formation of stoichiometric HA from CDHA. Therefore, the increased setting time observed upon increasing $\mathrm{Sr}^{2+}$ content may be due to either the reduced solubility of the Sr containing DCPD, SrDCPD or the inhibition of CDHA formation in the presence of $\mathrm{Sr}^{2+}$ ions. A similar increase in setting time was observed by Guo et. al upon increasing the $\mathrm{Sr}^{2+}$ content in the TTCP-DCPA-DSPA system using various concentrations of phosphoric acid as the liquid component [4]. The increased setting time was attributed to the inhibition of HA deposition by $\mathrm{Sr}^{2+}$ ions. However, it should be noted that the influence of $\mathrm{Sr}^{2+}$ on the solubility of DCPD is largely unexplored. 


\subsubsection{Phase Composition}

To further analyze the consumption of the cement precursors and subsequent formation of HA, $\mathrm{X}$-ray diffraction of the cement scaffolds after setting and after immersion in PBS, kept at $37^{\circ} \mathrm{C}$, for up to one week was performed. Figure 3 illustrates the diffraction data collected from samples after final setting and for all the compositions studied. After setting, peaks indicative of the presence of unreacted DCPD (JCPDS 09-0077) and TTCP (25-1137) were clearly identified. The XRD data collected after 3 days in PBS is illustrated in Figure 4. After immersion in PBS for 3 days, a reduction in the intensity of DCPD peaks was observed while poorly crystalline peaks indicative of the formation of increased amounts of HA (JCPDS 09-0432) were also detected with reduced amounts of unreacted TTCP as well remaining similar to the DCPD phase.

To more quantitatively study the phase composition of cement scaffolds both after setting and after immersion in PBS, Rietveld refinement was employed (Figure 5). After setting, a reduced amount of HA was detected in the cements prepared with increasing $\mathrm{Sr}^{2+}$ content in comparison to the unsubstituted or undoped cements (Figure 5a)), which would also suggest an increase in setting time for $\mathrm{Sr}^{2+}$ containing cements, as was previously observed (Table 3). However, after immersion in PBS a similar amount of HA was detected for all the compositions studied at later time points. After setting, the wt. $\%$ of both DCPD and TTCP in $\mathrm{Sr}^{2+}$ containing cements increased upon increasing $\mathrm{Sr}^{2+}$ content due to the reduced consumption of the reactants during the initial setting reaction (Figure 5b) and c)). After 24 hours in PBS, Sr substituted DCPD, solubilized at an increased rate in comparison to undoped DCPD. However after 7 days, DCPD was no longer detected for all the compositions studied with and without Sr. Interestingly, despite the use of excess DCPD in the cement setting reaction, greater than $25 \mathrm{wt}$ \% TTCP remained after 7 days for all the compositions. 
In the current study, a non-stoichiometric ratio of the reactants was used to enhance the influence of $\mathrm{Sr}^{2+}$ substitution in DCPD on cement properties. Despite the use of excess DCPD, the complete consumption of DCPD and remaining TTCP after 7 days in PBS at $37^{\circ} \mathrm{C}$ suggests that large amounts of DCPD may be lost due to dissolution which do not react with TTCP. A possible explanation may be limited diffusion of the DCPD dissolution products due to the formation of an initial layer of HA on the surface of TTCP particles thus retarding the consumption of TTCP [23]. Increased TTCP reactivity may be achieved either by using a smaller particle size or by mechanically milling to form a thin layer of highly reactive amorphous calcium phosphate as reported by Moseke et al [24].

\subsubsection{Elemental Composition of the Cement Scaffolds}

Due to concerns over large amounts of DCPD, the $\mathrm{Sr}^{2+}$ containing precursor, dissolving and not reacting with TTCP to form $\mathrm{Sr}^{2+}$ substituted HA, an elemental analysis of the cement scaffolds after setting and after immersion in PBS for 7 days was performed (Table 4). After setting and after 7 days in PBS, a slight reduction in the $(\mathrm{Ca}+\mathrm{Sr}) / \mathrm{P}$ ratio for all the conditions was observed. With respect to the $\mathrm{Sr} /(\mathrm{Ca}+\mathrm{Sr})$ value, very similar amounts of $\mathrm{Sr}^{2+}$ were measured for both $\mathrm{Sr}^{2+}$ containing compositions at either time point. After 7 days, either very little or no DCPD remained in the cement scaffolds (Figure 5 b)). Therefore, the similar $\mathrm{Sr}^{2+}$ concentration measured prior to immersion in PBS and after 7 days in PBS confirms that most of the $\mathrm{Sr}^{2+}$ added is retained in the scaffold despite the near complete consumption of DCPD. Based on the phase composition after 7 days (Figure 5), it can therefore be concluded that the $\mathrm{Sr}^{2+}$ retained in the cement has indeed formed SrHA. This result confirms that the use $\mathrm{Sr}^{2+}$ substituted $\mathrm{CaP}$ precursors in the form of $\mathrm{Sr}$ substituted DCPD directly rather than $\mathrm{Sr}^{2+}$ containing salts may be a 
useful approach to efficiently incorporate $\mathrm{Sr}^{2+}$ ions into the HA forming cements which is the primary goal of this study.

\subsubsection{Wet Compressive Strength and \% Porosity}

The compressive strength and \% porosity of the cement scaffolds generated after immersion in PBS for 24 hours and 7 days was also determined to correlate the phase composition with the mechanical properties (Table 5). Preformed cylindrical samples were tested immediately after removing from PBS. After 24 hours immersion in PBS, a compressive strength of 6.51 MPa was measured for the undoped and unsubstituted cements while values of 5.74 and $4.73 \mathrm{MPa}$ were obtained for cements prepared with 5 and 10\% Sr substitution in DCPD, namely 5\%SrDCPD and $10 \%$ SrDCPD, respectively. After 7 days, the compressive strengths for all the conditions increased due to the enhanced formation of HA (Figure 5). Comparable values were obtained for the cements prepared with both undoped and 5\% Sr in DCPD, 5\%SrDCPD while a slightly increased compressive strength was measured for samples prepared using $10 \% \mathrm{Sr}$ in DCPD, $10 \%$ SrDCPD.

The typical range of compressive strength values obtained for the $\mathrm{CaP}$ cements is known to be within 10-100 MPa. It should be noted that the compression strength of trabecular bone with which cement scaffolds are in direct contact with, is approximately $10 \mathrm{MPa}$ [25]. In many studies, cement pastes are compressed prior to setting which is known to reduce the inherent porosity, thus increasing the compressive strength [26]. In the current study, cement pastes were not compressed prior to setting and compressive strength values measured were similar to trabecular bone as indicated. To further analyze the cement scaffolds, the \% porosity was determined by measuring the true density, $\rho_{\mathrm{T}}$ and apparent density, $\rho_{\mathrm{A}}$ after 24 hours and 7 days 
in PBS (Table 5). As expected from the compressive strength results, the cements prepared with undoped and 5\% $\mathrm{Sr}$ containing DCPD, 5\% SrDCPD had an increased porosity at both time points in comparison to those prepared with $10 \% \mathrm{Sr}$ in DCPD, 10\% SrDCPD.

The reduced porosity and increased compressive strength for cements prepared with $10 \% \mathrm{Sr}$ in DCPD, $10 \%$ SrDCPD may be due to the slightly reduced DCPD particle size with increasing $\mathrm{Sr}^{2+}$ content (Figure 2). In the TTCP-DCPA cement system, a 10:1 TTCP:DCPA ratio in particle size was found to form cements with the best mechanical stability [24]. While the optimum particle size ratio for the TTCP-DCPD system is not known, the reduced particle size of $10 \% \mathrm{Sr}$ containing DCPD, $10 \%$ SrDCPD may be closer to the optimum particle size ratio to obtain the increased mechanical stability. In summary, similar compressive strength values to trabecular bone were obtained for the cements formed with $10 \% \mathrm{Sr}$ containing DCPD, $10 \% \mathrm{SrDCPD}$. Despite the near 50\% total porosity, the scaffolds formed for all the conditions were stable under aqueous conditions. The relatively high porosity may lead to increased protein adsorption upon exposure to physiological fluids which may in fact indeed support increased cell attachment and proliferation that could also likely contribute to improved resorption of the HA forming cement.

\subsection{MC3T3-E1 Proliferation}

MC3T3-E1 cells were seeded directly on the pre-formed cement scaffolds and cultured for up to two weeks in growth media to determine whether or not the cement scaffolds would support proliferation. Cell proliferation was quantified using the alamarblue assay at various time points (Figure 6). After 1 day, similar levels of proliferation were measured for all the conditions. After 3 days, an increase in proliferation was measured in comparison to 1 day for all the groups studied and a slight increase in fluorescence intensity was measured on cements prepared with 
increasing $\mathrm{Sr}^{2+}$ content. At later time points, a statistically significant increase in proliferation was measured on cements prepared with $10 \% \mathrm{Sr}$ containing DCPD, 10\% SrDCPD in comparison to all other groups. This data therefore suggests that cements prepared with up to $10 \% \mathrm{Sr}$ containing DCPD, 10\% SrDCPD support greater proliferation in comparison to the undoped or unsubstituted cements while similar levels of proliferation were observed for the cements prepared with 5\% Sr containing DCPD, 5\%SrDCPD and undoped DCPD.

$\mathrm{Sr}^{2+}$ has previously been reported to stimulate the proliferation of both osteoblasts and mesenchymal stem cells $[3,27]$. It has also been demonstrated to influence cellular processes through interactions with the calcium sensing receptor (CaSR) resulting in an increased gene expression of c-fos and egr1, which are both involved in the regulation of osteoblast proliferation [28]. Therefore, it is not surprising that cements prepared with increased $\mathrm{Sr}^{2+}$ stimulated the increased proliferation of mouse preosteoblast cells. However, $\mathrm{Sr}^{2+}$ concentrations greater than 1 $\mathrm{mM}$ have been shown to suppress the proliferation of mesenchymal stem cells drastically [7]. Therefore, based on these results it can be concluded that amounts of $\mathrm{Ca}^{2+}, \mathrm{Sr}^{2+}$, and $\mathrm{PO}_{4}{ }^{3-}$ released into the culture media from these HA forming cements prepared using a nonstoichiometric ratio of TTCP and Sr containing DCPD, SrDCPD are indeed non-toxic to MC3T3-E1 cells.

\subsection{Ionic Concentrations in Culture Media}

During the cell proliferation experiments, the culture media was collected on the days it was changed and analyzed. The $\mathrm{pH}$ and concentrations of $\mathrm{Ca}^{2+}, \mathrm{Sr}^{2+}$, and $\mathrm{PO}_{4}{ }^{3-}$ in the culture media were accordingly measured (Figure 7). Despite the use of excess DCPD, the $\mathrm{pH}$ remained slightly basic and similar to physiological conditions throughout the experiment for all the 
conditions (Figure 7a)). The basal concentrations of $\mathrm{Ca}^{2+}$ and $\mathrm{PO}_{4}{ }^{3-}$ in the MC3T3-E1 growth media were approximately 1.7 and $0.9 \mathrm{mM}$, respectively. After 1 day of incubation with cement samples, $\mathrm{Ca}^{2+}$ concentration was approximately $1 \mathrm{mM}$ for all the conditions and gradually decreased throughout the 15 day culture period (Figure 7 b)). A sustained release of $\mathrm{Sr}^{2+}$ ranging from $0.02-0.05 \mathrm{mM}$ during the culture period was observed for the cements prepared with SrDCPD (Figure 7 c)). In contrast to $\mathrm{Ca}^{2+}$ concentration, a gradual increase in $\mathrm{PO}_{4}{ }^{3-}$ concentration was observed throughout the culture period (Figure $7 \mathbf{d}$ )).

The reduced $\mathrm{Ca}^{2+}$ concentration from basal levels suggests that the mineral was deposited from the culture media onto the surface of the cement samples throughout the two week experiment. Although $\mathrm{PO}_{4}{ }^{3-}$ was also consumed during the mineral formation, the increase in $\mathrm{PO}_{4}{ }^{3-}$ concentration from basal levels is most likely due to dissolution of excess DCPD since a nonstoichiometric amount of DCPD was used and little or no DCPD was detected after 7 days during immersion in PBS (Figure 5 b)). Although either very little or no DCPD remained after 7 days in PBS, a sustained release of $\mathrm{Sr}^{2+}$ was detected at time points greater than 7 days in culture media. This result is most likely due to different rates of dissolution of the various calcium phosphate phases in the presence of culture media containing $\mathrm{Ca}^{2+}$ and serum proteins in comparison to PBS, which did not contain either $\mathrm{Ca}^{2+}$ or serum proteins [29].

In a study where postmenopausal women were treated with strontium ranelate, the baseline concentration of $\mathrm{Sr}^{2+}$ in the serum was $0.3 \mu \mathrm{M}$ and after three months of treatment it had risen to 117.9 $\mu \mathrm{M}$ [30]. Previous work by Schumacher et. al has also shown that with human mesenchymal stem cells a slight increase in proliferation was observed when cells were cultured in media containing up to $0.1 \mathrm{mM}$ of $\mathrm{Sr}^{2+}$ [7]. In the same study, with respect to osteogenic differentiation, increased ALP activity was observed at earlier time points for mesenchymal stem 
cells cultured in osteogenic media containing between $0.01-0.1 \mathrm{mM} \mathrm{Sr}^{2+}$, which is similar to the serum concentration observed during strontium ranelate treatment. Although MC3T3-E1 cells were used in the current study, the amount of $\mathrm{Sr}^{2+}$ released into the culture media throughout the experiment from cement scaffolds is within the optimum range of $\mathrm{Sr}^{2+}$ concentration to support both mesenchymal stem cell proliferation and differentiation based on the previously published data.

\subsection{MC3T3-E1 Osteogenic Differentiation}

After confirming that $\mathrm{Sr}^{2+}$ containing cements were capable of supporting MC3T3-E1 proliferation and released sufficient amounts of $\mathrm{Sr}^{2+}$ that may also support osteogenic differentiation, MC3T3-E1 differentiation was evaluated by measuring ALP activity and the intracellular concentrations of osteoprotegerin (OPG) and osteocalcin (OCN). The ALP activity of cells cultured for 10 and 21 days in osteogenic media seeded directly on pre-formed cement scaffolds is illustrated in Figure 8 a). Similar to the results observed from the alamarblue proliferation assay, comparable levels of ALP activity were observed between all groups at earlier time points. However, after 21 days increased levels of ALP activity were measured from the cells cultured on cements prepared with both 5 and $10 \% \mathrm{Sr}$ containing DCPD, i.e. $5 \% \mathrm{SrDCPD}$ and $10 \% \mathrm{SrDCPD}$ in comparison to undoped cements. A near $50 \%$ increase in comparison to undoped cements was observed for cells cultured on cement scaffolds prepared with $10 \%$ Sr containing DCPD, 10\% SrDCPD.

The expression of two osteogenic proteins, OPG and OCN, was measured after 21 days to further assess osteogenic differentiation on cements prepared with varying amounts of $\mathrm{Sr}^{2+}$ (Figure 8 b)). For cells cultured directly on cement substrates, significantly increased levels of 
OPG were measured on cements prepared with both 5 and $10 \% \mathrm{Sr}$ containing DCPD, i.e. $5 \% \mathrm{SrDCPD}$ and $10 \% \mathrm{SrDCPD}$ in comparison to undoped cements. A similar trend was also observed in OCN expression after 21 days. Elevated levels of OCN were measured on cements prepared with 5 and 10\% Sr containing DCPD, i.e. 5\%SrDCPD and 10\%SrDCPD while much lower concentrations of OCN were measured on undoped cements.

The capability of $\mathrm{Sr}^{2+}$ containing cements to support osteogenic differentiation may be due to either the chemical or physical cues provided by the scaffold during direct culture. Therefore, to study osteogenic differentiation in the absence of physical contact with the cement substrates while maintaining similar ionic concentrations to direct cell culture experiments, permeable transwell inserts were used. ALP activity and the expression of OPG and OCN after 21 days in osteogenic media were once again determined. In contrast to the results observed during direct culture experiments, similar levels of ALP activity were measured for cells cultured indirectly with all the cement compositions after both 10 and 21 days (Figure 8 c)). OPG and OCN concentration after 21 days also exhibited similar trends to those observed for ALP activity where a comparable expression of both osteogenic proteins was observed for all conditions (Figure 8 d)).

This data suggests that cells cultured directly on cement scaffolds prepared with $\mathrm{Sr}^{2+}$ experience increased levels of differentiation either due to the microstructure of $\mathrm{Sr}^{2+}$ containing cement scaffolds or the increased local $\mathrm{Sr}^{2+}$ concentration that the cells are exposed to near the scaffold surface. $\mathrm{Sr}^{2+}$ ions are known to interact with cells through either the CaSRs or non-selective $\mathrm{Ca}^{2+}$ channels which may initiate Wnt and other signaling pathways that regulate osteogenic differentiation [31]. However, in addition to $\mathrm{Ca}^{2+}, \mathrm{PO}_{4}{ }^{3-}$, and $\mathrm{Sr}^{2+}$ concentration, $\mathrm{CaP}$ microstructure has also been demonstrated to influence cell proliferation and differentiation [32]. 
Therefore, to further assess the role of $\mathrm{Sr}^{2+}$ release and scaffold microstructure in supporting osteogenic differentiation noted above, the blocking of either CaSRs or the signaling pathways known to be activated upon exposure to $\mathrm{Sr}^{2+}$ ions is required and will be performed in future studies.

\subsection{RAW264.7 TRAP Activity and Morphology}

In addition to osteoblasts, it is known that osteoclasts also play a key role in bone remodeling. In the current study RAW264.7 cells, a murine monocyte cell line, were seeded directly on the cement samples. The cells were cultured for up to 10 days in media supplemented with $50 \mathrm{ng}$ $\mathrm{mL}^{-1}$ of RANKL, a key growth factor in osteoclast development [33]. TRAP activity and cell morphology were analyzed to study the influence of varying $\mathrm{Sr}^{2+}$ content in $\mathrm{HA}$ forming $\mathrm{CaP}$ cements on the osteoclastic differentiation of RAW264.7 cells. With respect to TRAP activity, after 5 days similar values were observed between the three conditions (Figure 9). After 10 days however, a two to three fold increase in TRAP activity was observed. At both time points, no statistically significant differences were observed upon varying $\mathrm{Sr}^{2+}$ content.

In addition to increased TRAP activity, the formation of multinucleated cells is considered characteristic of the differentiation of monocytes towards mature osteoclasts. Therefore, after 10 days of culture in RANKL, the cells cultured on cement scaffolds were fixed using paraformaldehyde and cytoskeletal staining was performed (Figure 10). On tissue culture plastic several $200 \mu \mathrm{m}$ or greater multinucleated cells were observed (Figure 10 a)). However, on cement samples similar cell aggregates were observed but the large well defined actin rings observed for the cells cultured on tissue culture plastic were not detected (Figure 10 b)-d)). In 
comparing the cement samples, slightly larger cell aggregates were observed on cements prepared with $10 \%$ SrDCPD. However, no substantial differences were observed.

Similar to osteoblasts, osteoclasts can also be stimulated by many ions through CaSRs [3]. Interestingly, $\mathrm{Sr}^{2+}$ has been reported to inhibit the differentiation of monocytes towards mature osteoclasts. However, in the current study no statistically significant differences in TRAP activity or multinuclear cell formation was observed. This result suggests that the amount of $\mathrm{Sr}^{2+}$ released into the culture media may be too low to inhibit osteoclastic differentiation in comparison to cells cultured on undoped HA forming cements.

\section{Conclusion}

$\mathrm{Sr}^{2+}$ substituted HA forming cements were prepared using TTCP and directly synthesized SrDCPD as cement precursors. The setting time increased with increasing $\mathrm{Sr}^{2+}$ content which may be due to the inhibition of HA formation in the presence of $\mathrm{Sr}^{2+}$. Similar amounts of $\mathrm{Sr}^{2+}$ were measured in the cements formed both after setting and after immersion in PBS for up to one week suggesting that most of the $\mathrm{Sr}^{2+}$ introduced was incorporated into the HA formed. An increase in compressive strength was also measured for cements prepared with increasing $\mathrm{Sr}^{2+}$ content after immersion in PBS for 7 days. $\mathrm{Sr}^{2+}$ substituted cements supported increased MC3T3E1 proliferation and differentiation in comparison to undoped cements. Interestingly, both the release of $\mathrm{Sr}^{2+}$ ions and cement microstructure appeared to support osteogenic differentiation. Despite the differences in the amount of $\mathrm{Sr}^{2+}$ incorporated into and released from the cement scaffolds, no statistically significant difference in the osteoclastic differentiation of RAW264.7 
cells was observed. These results indicate that the use of $\mathrm{Sr}^{2+}$ substituted calcium phosphate precursors rather than $\mathrm{Sr}^{2+}$ containing salts may be a simplified approach to prepare biologically viable $\mathrm{Sr}^{2+}$ substituted HA forming cements.

\section{Acknowledgments}

The authors gratefully acknowledge the University of Pittsburgh, Edward R. Weidlein Chair Professorship funds, the NSF-ERC-Revolutionizing Metallic Biomaterials (Grant\# EEC0812348) and NSF-CBET 0933153 for supporting this research. Additionally, PNK would like to acknowledge the University of Pittsburgh, and the Center for Complex Engineered Multifunctional Materials (CCEMM), Department of Bioengineering, Swanson School of Engineering for providing valuable equipment and infrastructure needed to execute the current study.

\section{References}

[1] Yang F, Yang D, Tu J, Zheng Q, Cai L, Wang L. Strontium Enhances Osteogenic Differentiation of Mesenchymal Stem Cells and In Vivo Bone Formation by Activating Wnt/Catenin Signaling. Stem Cells 2011;29:981-91.

[2] Ni GX, Lu WW, Tang B, Ngan AHW, Chiu KY, Cheung KMC, et al. Effect of weight-bearing on bone-bonding behavior of strontium-containing hydroxyapatite bone cement. Journal of Biomedical Materials Research - Part A 2007;83:570-6.

[3] Habibovic P, Barralet JE. Bioinorganics and biomaterials: Bone repair. Acta Biomaterialia 2011;7:3013-26.

[4] Guo D, Xu K, Zhao X, Han Y. Development of a strontium-containing hydroxyapatite bone cement. Biomaterials 2005;26:4073-83.

[5] Bohner M. DESIGN OF CERAMIC-BASED CEMENTS AND PUTTIES FOR BONE GRAFT SUBSTITUTION. European Cells \& Materials 2010;20:1-12.

[6] Dorozhkin SV. Calcium orthophosphate cements for biomedical application. Journal of Materials Science 2008;43:3028-57.

[7] Schumacher M, Lode A, Helth A, Gelinsky M. A novel strontium(II)-modified calcium phosphate bone cement stimulates human-bone-marrow-derived mesenchymal stem cell proliferation and osteogenic differentiation in vitro. Acta Biomaterialia 2013;9:9547-57.

[8] Schumache M, Henß A, Rohnke M, Gelinsky M. A novel and easy-to-prepare strontium(II) modified calcium phosphate bone cement with enhanced mechanical properties. Acta Biomaterialia 2013;9:753644. 
[9] Panzavolta S, Torricelli P, Sturba L, Bracci B, Giardino R, Bigi A. Setting properties and in vitro bioactivity of strontium-enriched gelatin-calcium phosphate bone cements. Journal of Biomedical Materials Research - Part A 2008;84:965-72.

[10] Boanini E, Panzavolta S, Rubini K, Gandolfi M, Bigi A. Effect of strontium and gelatin on the reactivity of $\alpha$-tricalcium phosphate. Acta Biomaterialia 2010;6:936-42.

[11] Jegou Saint-Jean S, Camiré CL, Nevsten P, Hansen S, Ginebra MP. Study of the reactivity and in vitro bioactivity of Sr-substituted $\alpha$-TCP cements. Journal of Materials Science: Materials in Medicine 2005;16:993-1001.

[12] Dagang G, Xu K, Han Y. The influence of Sr doses on the in vitro biocompatibility and in vivo degradability of single-phase Sr-incorporated HAP cement. Journal of Biomedical Materials Research Part A 2008;86:947-58.

[13] Lee D, Sfeir C, Kumta PN. Novel in-situ synthesis and characterization of nanostructured magnesium substituted beta-tricalcium phosphate (beta-TCMP). Materials Science \& Engineering CBiomimetic and Supramolecular Systems 2009;29:69-77.

[14] Temizel N, Girisken G, Tas AC. Accelerated transformation of brushite to octacalcium phosphate in new biomineralization media between $36.5{ }^{\circ} \mathrm{c}$ and $80^{\circ} \mathrm{c}$. Materials Science and Engineering C 2011;31:1136-43.

[15] Boanini E, Gazzano M, Bigi A. Ionic substitutions in calcium phosphates synthesized at low temperature. Acta Biomaterialia 2010;6:1882-94.

[16] Rokita E, Hermes C, Nolting HF, Ryczek J. Substitution of calcium by strontium within selected calcium phosphates. Journal of Crystal Growth 1993;130:543-52.

[17] Alkhralsat MH, Marino FT, Rodriguez CR, Jerez LB, Cabarcos EL. Combined effect of strontium and pyrophosphate on the properties of brushite cements. Acta Biomaterialia 2008;4:664-70.

[18] LeGeros RZ, LeGeros JP. Brushite crystals grown by diffusion in silica gel and in solution. Journal of Crystal Growth 1972;13-14:476-80.

[19] Burguera EF, Xu HHK, Takagi S, Chow LC. High early strength calcium phosphate bone cement: Effects of dicalcium phosphate dihydrate and absorbable fibers. Journal of Biomedical Materials Research - Part A 2005;75:966-75.

[20] Takagi S, Chow LC, Ishikawa K. Formation of hydroxyapatite in new calcium phosphate cements. Biomaterials 1998;19:1593-9.

[21] Fulmer MT, Brown PW. Hydrolysis of dicalcium phosphate dihydrate to hydroxyapatite. Journal of Materials Science: Materials in Medicine 1998;9:197-202.

[22] Greish YE, Brown PW. Phase Evolution during the Formation of Stoichiometric Hydroxyapatite at $37.4{ }^{\circ}$ C. Journal of Biomedical Materials Research - Part B Applied Biomaterials 2003;67:632-7.

[23] Gbureck U, Barralet JE, Hofmann MP, Thull R. Nanocrystalline tetracalcium phosphate cement. Journal of Dental Research 2004;83:425-8.

[24] Moseke C, Gbureck U. Tetracalcium phosphate: Synthesis, properties and biomedical applications. Acta Biomaterialia 2010;6:3815-23.

[25] Dorozhkin SV. Calcium orthophosphate cements and concretes. Materials 2009;2:221-91.

[26] Burguera EF, Guitián F, Chow LC. A water setting tetracalcium phosphate-dicalcium phosphate dihydrate cement. Journal of Biomedical Materials Research - Part A 2004;71:275-82.

[27] Zhang W, Shen Y, Pan H, Lin K, Liu X, Darvell BW, et al. Effects of strontium in modified biomaterials. Acta Biomaterialia 2011;7:800-8.

[28] Chattopadhyay N, Quinn SJ, Kifor O, Ye C, Brown EM. The calcium-sensing receptor (CaR) is involved in strontium ranelate-induced osteoblast proliferation. Biochemical Pharmacology 2007;74:43847.

[29] Hemingway CA, Shellis RP, Parker DM, Addy M, Barbour ME. Inhibition of hydroxyapatite dissolution by ovalbumin as a function of $\mathrm{pH}$, calcium concentration, protein concentration and acid type. Caries Research 2008;42:348-53. 
[30] Meunier PJ, Roux C, Seeman E, Ortolani S, Badurski JE, Spector TD, et al. The Effects of Strontium Ranelate on the Risk of Vertebral Fracture in Women with Postmenopausal Osteoporosis. New England Journal of Medicine 2004;350:459-68.

[31] Fielding GA, Smoot W, Bose S. Effects of $\mathrm{SiO} 2, \mathrm{SrO}, \mathrm{MgO}$, and $\mathrm{ZnO}$ dopants in tricalcium phosphates on osteoblastic Runx2 expression. Journal of Biomedical Materials Research - Part A 2013.

[32] Honda Y, Anada T, Kamakura S, Morimoto S, Kuriyagawa T, Suzuki O. The effect of microstructure of octacalcium phosphate on the bone regenerative property. Tissue Engineering - Part A 2009;15:1965-73.

[33] Detsch R, Boccaccini AR. The role of osteoclasts in bone tissue engineering. Journal of Tissue Engineering and Regenerative Medicine 2014.

\section{Table Captions}

Table 1. The amounts (expressed as $10^{-3}$ moles) of $\mathrm{Ca}^{2+}, \mathrm{Sr}^{2+}$, and $\mathrm{PO}_{4}{ }^{3-}$ containing precursors used in the synthesis of dicalcium phosphate dihydrate (DCPD).

Table 2. The elemental compositions of DCPD precipitated with and without $\mathrm{Sr}^{2+}$ obtained by ICP.

Table 3. The setting times at $37^{\circ} \mathrm{C}$ for cements prepared with a 55:45 TTCP:DCPD ratio by weight and a P/L ratio of $2.2 \mathrm{~g} \mathrm{~mL}^{-1}$. Four repeats were performed for each condition.

Table 4. The elemental composition of cement powders after setting and after immersion in PBS at $37^{\circ} \mathrm{C}$ for 7 days. Four repeats were performed for each condition.

Table 5. The wet compressive strength and \% porosity of cement samples after incubation in PBS at $37^{\circ} \mathrm{C}$ for 1 and 7 days. The $\%$ porosity was calculated using the formula $1-\left(\rho_{\mathrm{A}} / \rho_{\mathrm{T}}\right)$, where ' $\rho_{\mathrm{A}}$ ' is the apparent density and ' $\rho_{\mathrm{T}}$ ' is the true density. A total of six repeats were performed for each condition.

\section{Figure Captions}

Figure 1. The X-ray diffraction patterns of i) DCPD (JCPDS 09-0077), ii) undoped DCPD, iii) $5 \%$ Sr DCPD, and iv) $10 \%$ Sr DCPD after drying overnight under vacuum.

Figure 2. The microstructure of DCPD particles precipitated a) without $\mathrm{Sr}^{2+}$, b) with $5 \% \mathrm{Sr}^{2+}$, and c) with $10 \% \mathrm{Sr}^{2+}$.

Figure 3. X-ray diffraction patterns of i) DCPD (JCPDS 09-0077), ii) TTCP (JCPDS 25-1137), iii) HA (JCPDS 09-0432), and cement samples after final setting prepared with iv) undoped or unsubstituted DCPD, v) 5\% Sr containing DCPD, Sr DCPD, and vi) 10\% Sr containing DCPD, SrDCPD. 
Figure 4. X-ray diffraction patterns of i) DCPD (JCPDS 09-0077), ii) TTCP (JCPDS 25-1137), iii) HA (JCPDS 09-0432), and cement samples after 3 days in $\mathrm{PBS}$ at $37^{\circ} \mathrm{C}$ prepared with iv) undoped DCPD, v) 5\% Sr DCPD, and vi) 10\% Sr DCPD.

Figure 5. The weight $\%$ of a) HA, b) DCPD, and c) TTCP in cement samples after setting and after immersion in PBS at $37^{\circ} \mathrm{C}$ for 1,3 , and 7 days determined using Rietveld refinement. Four repeats were performed for each condition at each time point.

Figure 6. MC3T3-E1 cell proliferation determined using the alamarblue assay after culturing on cements prepared using undoped, 5, and 10\% Sr DCPD for up to 15 days in growth media. Four repeats were performed for each condition. A p value of $<0.05$ was considered significant.

Figure 7. The a) $\mathrm{pH}$ and concentrations of b) $\mathrm{Ca}^{2+}$, c) $\mathrm{Sr}^{2+}$, and d) $\mathrm{PO}_{4}{ }^{3-}$ in culture media during MC3T3-E1 viability experiments on cements prepared with undoped, 5\% $\mathrm{Sr}$, and $10 \% \mathrm{Sr}$ containing DCPD, i.e. 5\%SrDCPD, 10\% SrDCPD.

Figure 8. Alkaline phosphatase activity after 10 and 21 days and osteogenic protein expression after 21 days of MC3T3-E1 cells cultured a)-b) directly on cement scaffolds and c)-d) indirectly with cement scaffolds in osteogenic media. Four repeats were performed for each condition. A p value of $<0.05$ was considered significant.

Figure 9. Tartarate resistant acidic phosphatase (TRAP) activity of RAW 264.7 cells cultured directly on cement scaffolds in media supplemented with $50 \mathrm{ng}^{*} \mathrm{~mL}^{-1}$ of RANKL. Four repeats were performed for each condition. A $\mathrm{p}$ value of $<0.05$ was considered significant.

Figure 10. Cytoskeletal staining of RAW 264.7 cells cultured a) on culture plastic, and directly on cement scaffolds prepared with b) undoped DCPD, c) 5\% Sr containing DCPD, 5\% SrDCPD, and d) $10 \%$ Sr containing DCPD, 10\%SrDCPD in media supplemented with $50 \mathrm{ng} \mathrm{mL}^{-1}$ of RANKL for 10 days. 


\begin{tabular}{cccc}
\hline & $\mathbf{C a C l}_{\mathbf{2}} \cdot \mathbf{2} \mathbf{H}_{\mathbf{2}} \mathbf{O}$ & $\mathbf{S r C l}_{\mathbf{2}} \cdot \mathbf{6} \mathbf{H}_{\mathbf{2}} \mathbf{O}$ & $\mathbf{N a}_{\mathbf{2}} \mathbf{H P O}_{\mathbf{4}}$ \\
\hline Undoped & 50 & - & 50 \\
$5 \% \mathrm{Sr}$ & 47.5 & 2.5 & 50 \\
$10 \% \mathrm{Sr}$ & 45 & 5 & 50 \\
\hline
\end{tabular}

Table 1. The amounts (expressed as $10^{-3}$ moles) of $\mathrm{Ca}^{2+}, \mathrm{Sr}^{2+}$, and $\mathrm{PO}_{4}{ }^{3-}$ containing precursors used in the synthesis of dicalcium phosphate dihydrate (DCPD). 


\begin{tabular}{cccccc}
\hline & Mol. \% Ca & Mol. \% Sr & Mol. \% P & Sr/(Ca+Sr) & $(\mathbf{C a}+$ Sr)/P \\
\hline Undoped & $50.6 \pm 0.2$ & - & $49.4 \pm 0.2$ & - & $1.02 \pm 0.01$ \\
$5 \% \mathrm{Sr}$ & $48.9 \pm 0.3$ & $2.2 \pm 0.1$ & $48.9 \pm 0.4$ & $4.30 \pm 0.12 \%$ & $1.05 \pm 0.02$ \\
$10 \% \mathrm{Sr}$ & $45.9 \pm 0.1$ & $4.4 \pm 0.0$ & $49.7 \pm 0.7$ & $8.84 \pm 0.03 \%$ & $1.01 \pm 0.01$ \\
\hline
\end{tabular}

Table 2. The elemental compositions of DCPD precipitated with and without Sr2+ obtained by ICP. 


\begin{tabular}{ccccc}
\hline & $\begin{array}{c}\text { First Setting } \\
\text { time with } \mathbf{H}_{\mathbf{2}} \mathbf{O} \\
\text { (mins) }\end{array}$ & $\begin{array}{c}\text { Final Setting } \\
\text { time with } \mathbf{H}_{\mathbf{2}} \mathbf{O} \\
\text { (mins) }\end{array}$ & $\begin{array}{c}\text { First Setting } \\
\text { time with 1.25\% } \\
\mathbf{N a}_{\mathbf{2}} \mathbf{H P O}_{4} \text { (mins) }\end{array}$ & $\begin{array}{c}\text { Final Setting } \\
\text { time with 1.25\% } \\
\mathbf{N a}_{\mathbf{2}} \mathbf{H P O}_{4} \text { (mins) }\end{array}$ \\
\hline Undoped & $18.5 \pm 0.5$ & $26.2 \pm 1.8$ & $4.0 \pm 0.5$ & $6.3 \pm 0.1$ \\
$5 \% \mathrm{Sr}$ & $20.3 \pm 1.1$ & $36.3 \pm 3.1$ & $6.4 \pm 0.4$ & $9.9 \pm 0.8$ \\
$10 \% \mathrm{Sr}$ & $33.8 \pm 2.1$ & $>60$ & $6.9 \pm 0.3$ & $12.0 \pm 1.4$ \\
\hline
\end{tabular}

Table 3. The setting times at $37^{\circ} \mathrm{C}$ for cements prepared with a 55:45 TTCP:DCPD ratio by weight and a P/L ratio of $2.2 \mathrm{~g} \mathrm{~mL}^{-1}$. Four repeats were performed for each condition. 


\begin{tabular}{ccccc}
\hline & $\begin{array}{c}(\mathbf{C a}+\mathbf{S r}) / \mathbf{P} \\
\text { after setting }\end{array}$ & $\begin{array}{c}(\mathbf{C a}+\mathbf{S r}) / \mathbf{P} \\
\text { after 7 days in } \\
\text { PBS }\end{array}$ & $\begin{array}{c}\mathbf{S r} /(\mathbf{C a}+\mathbf{S r}) \\
\text { after setting }\end{array}$ & $\begin{array}{c}\mathbf{S r} /(\mathrm{Ca}+\mathbf{S r}) \\
\text { after 7 days in } \\
\text { PBS }\end{array}$ \\
\hline Undoped & $1.50 \pm 0.01$ & $1.46 \pm 0.01$ & - & - \\
$5 \% \mathrm{Sr}$ & $1.50 \pm 0.01$ & $1.46 \pm 0.01$ & $1.30 \pm 0.01 \%$ & $1.34 \pm 0.01 \%$ \\
$10 \% \mathrm{Sr}$ & $1.49 \pm 0.01$ & $1.45 \pm 0.01$ & $2.68 \pm 0.02 \%$ & $2.65 \pm 0.03 \%$ \\
\hline
\end{tabular}

Table 4. The elemental composition of cement powders after setting and after immersion in PBS at $37^{\circ} \mathrm{C}$ for 7 days. Four repeats were performed for each condition. 


\begin{tabular}{ccccc}
\hline & $\begin{array}{c}\text { CS After 1 } \\
\text { day in PBS } \\
\text { (MPa) }\end{array}$ & $\begin{array}{c}\text { CS After 7 } \\
\text { days in PBS } \\
\text { (MPa) }\end{array}$ & $\begin{array}{c}\text { \% Porosity } \\
\text { After 1 day in } \\
\text { PBS }\end{array}$ & $\begin{array}{c}\text { \% Porosity } \\
\text { After 7 days } \\
\text { in PBS }\end{array}$ \\
\hline Undoped & $6.51 \pm 0.96$ & $8.84 \pm 0.82$ & $49.1 \pm 1.6$ & $50.8 \pm 0.9$ \\
$5 \% \mathrm{Sr}$ & $5.74 \pm 1.23$ & $8.55 \pm 1.12$ & $49.6 \pm 0.4$ & $51.9 \pm 1.0$ \\
$10 \% \mathrm{Sr}$ & $4.73 \pm 0.36$ & $10.94 \pm 2.33$ & $40.8 \pm 1.3$ & $40.4 \pm 0.1$ \\
\hline
\end{tabular}

Table 5. The wet compressive strength and $\%$ porosity of cement samples after incubation in PBS at $37^{\circ} \mathrm{C}$ for 1 and 7 days. The $\%$ porosity was calculated using the formula $1-\left(\rho_{\mathrm{A}} / \rho_{\mathrm{T}}\right)$, where ' $\rho_{\mathrm{A}}$ ' is the apparent density and ' $\rho_{\mathrm{T}}$ ' is the true density. A total of six repeats were performed for each condition. 


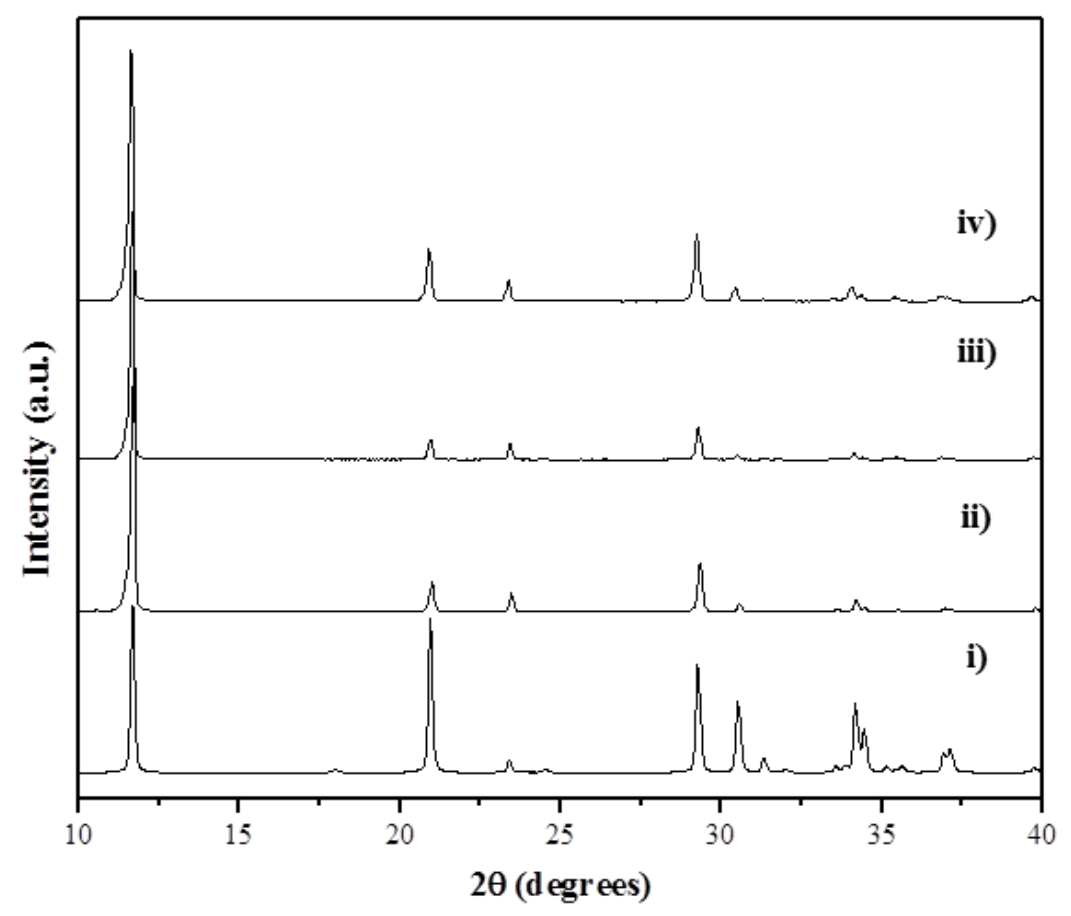

Figure 1. The X-ray diffraction patterns of i) DCPD (JCPDS 09-0077), ii) unsubstituted DCPD, iii) $5 \%$ Sr DCPD, and iv) $10 \%$ Sr DCPD after drying overnight under vacuum. 
a)

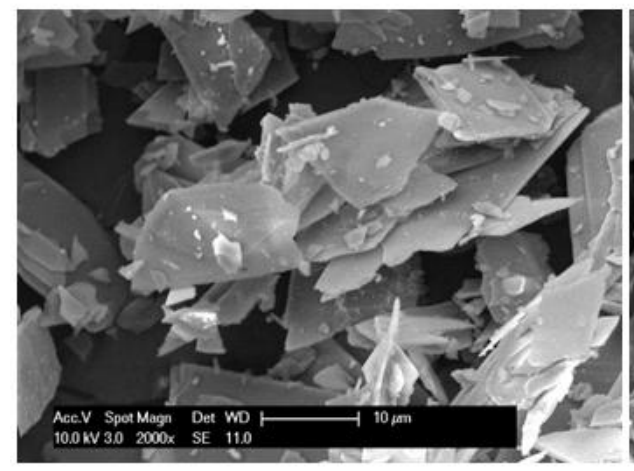

b)

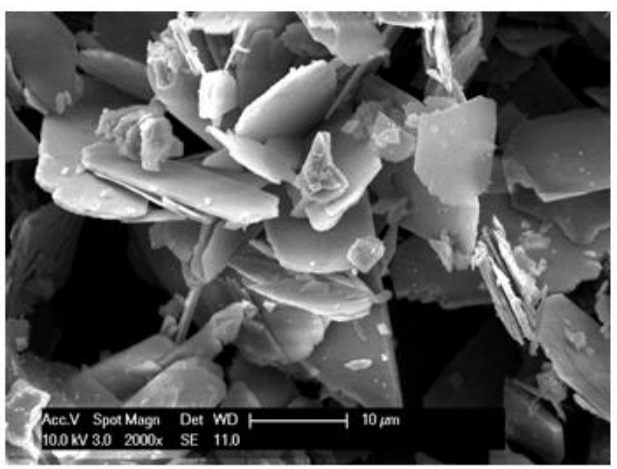

c)

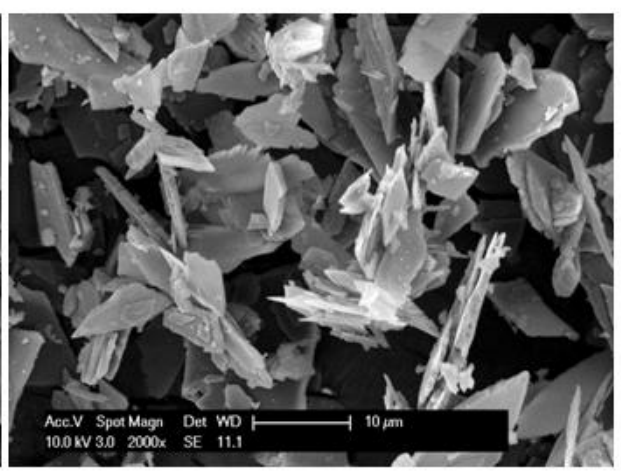

Figure 2. The microstructure of DCPD particles precipitated a) without $\mathrm{Sr}^{2+}$, b) with $5 \% \mathrm{Sr}^{2+}$, and c) with $10 \% \mathrm{Sr}^{2+}$. 


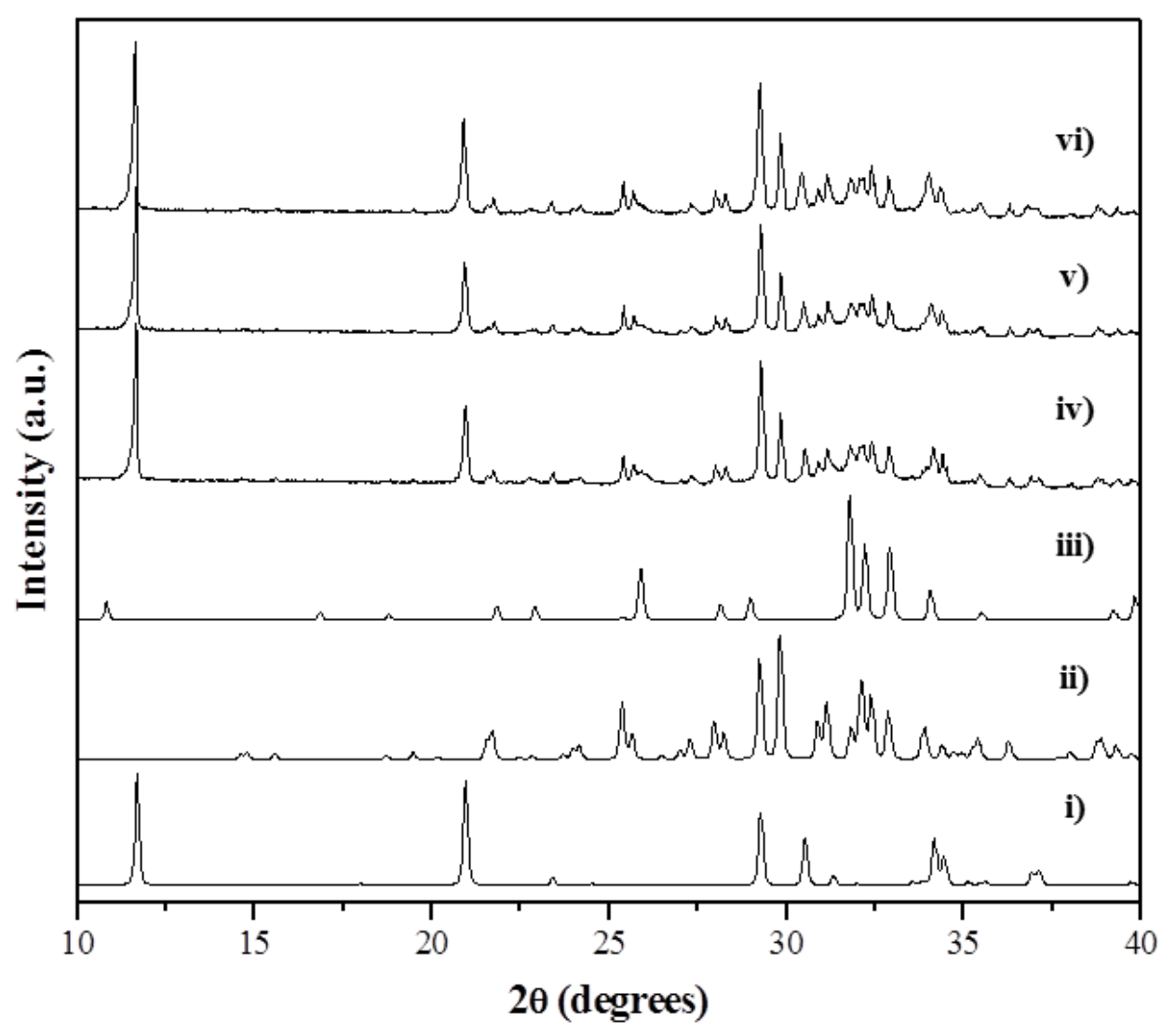

Figure 3. X-ray diffraction patterns of i) DCPD (JCPDS 09-0077), ii) TTCP (JCPDS 25-1137), iii) HA (JCPDS 09-0432), and cement samples after final setting prepared with iv) undoped or unsubstituted DCPD, v) 5\% Sr containing DCPD, Sr DCPD, and vi) 10\% Sr containing DCPD, SrDCPD. 


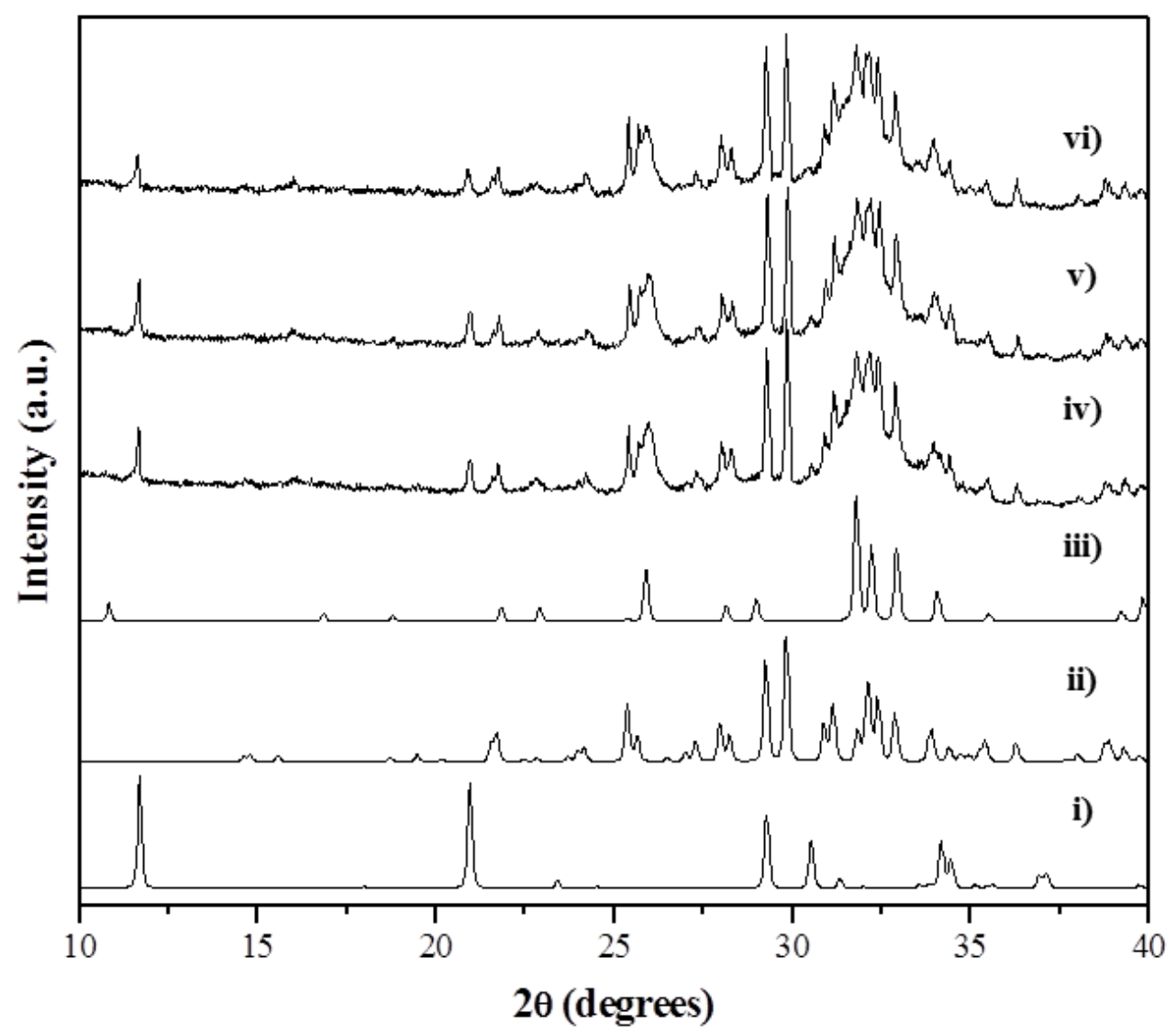

Figure 4. X-ray diffraction patterns of i) DCPD (JCPDS 09-0077), ii) TTCP (JCPDS 25-1137), iii) HA (JCPDS 09-0432), and cement samples after 3 days in PBS at $37^{\circ} \mathrm{C}$ prepared with iv) undoped DCPD, v) 5\% Sr DCPD, and vi) 10\% Sr DCPD. 
a)

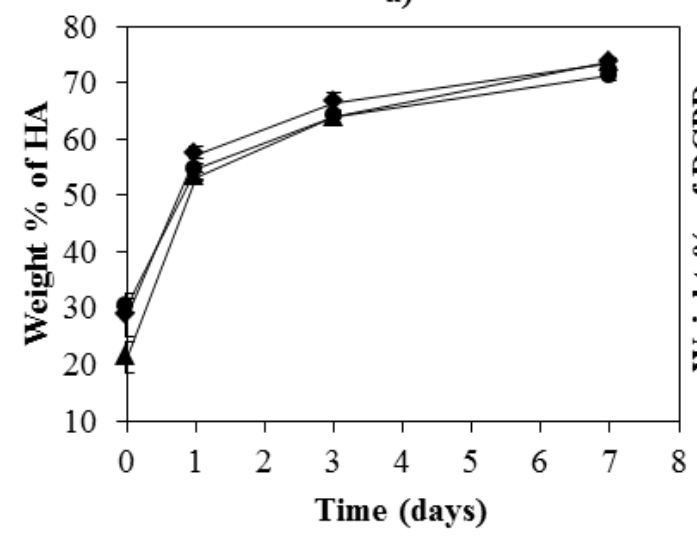

b)

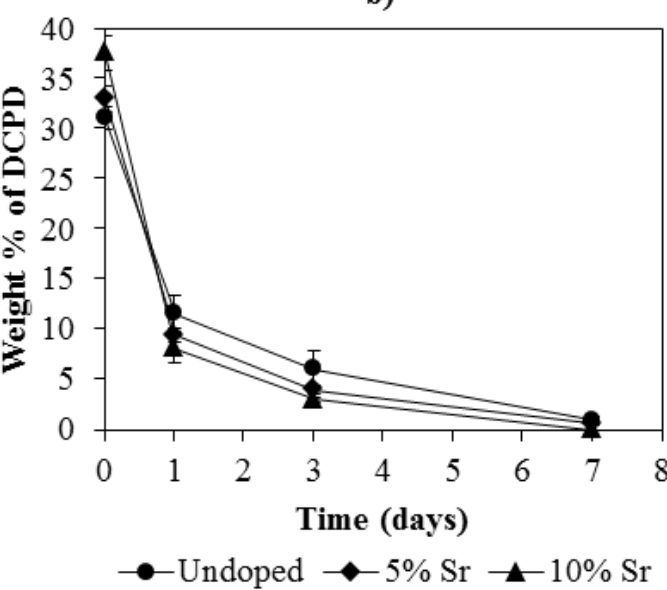

c)

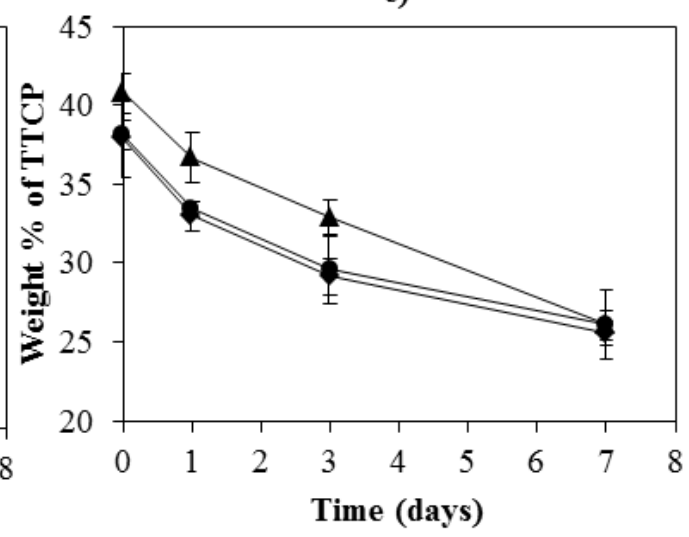

Figure 5. The weight $\%$ of a) HA, b) DCPD, and c) TTCP in cement samples after setting and after immersion in PBS at $37^{\circ} \mathrm{C}$ for 1,3 , and 7 days determined using Rietveld refinement. Four repeats were performed for each condition at each time point. 


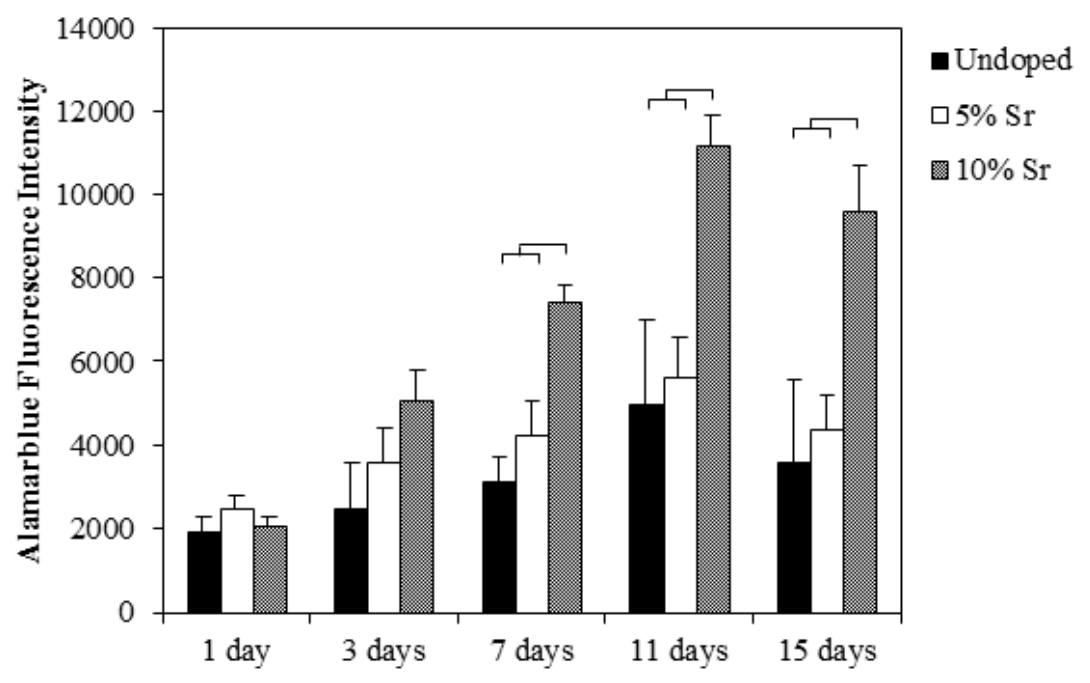

Figure 6. MC3T3-E1 cell proliferation determined using the alamarblue assay after culturing on cements prepared using undoped, 5, and 10\% Sr DCPD for up to 15 days in growth media. Four repeats were performed for each condition. A $p$ value of $<0.05$ was considered significant. 

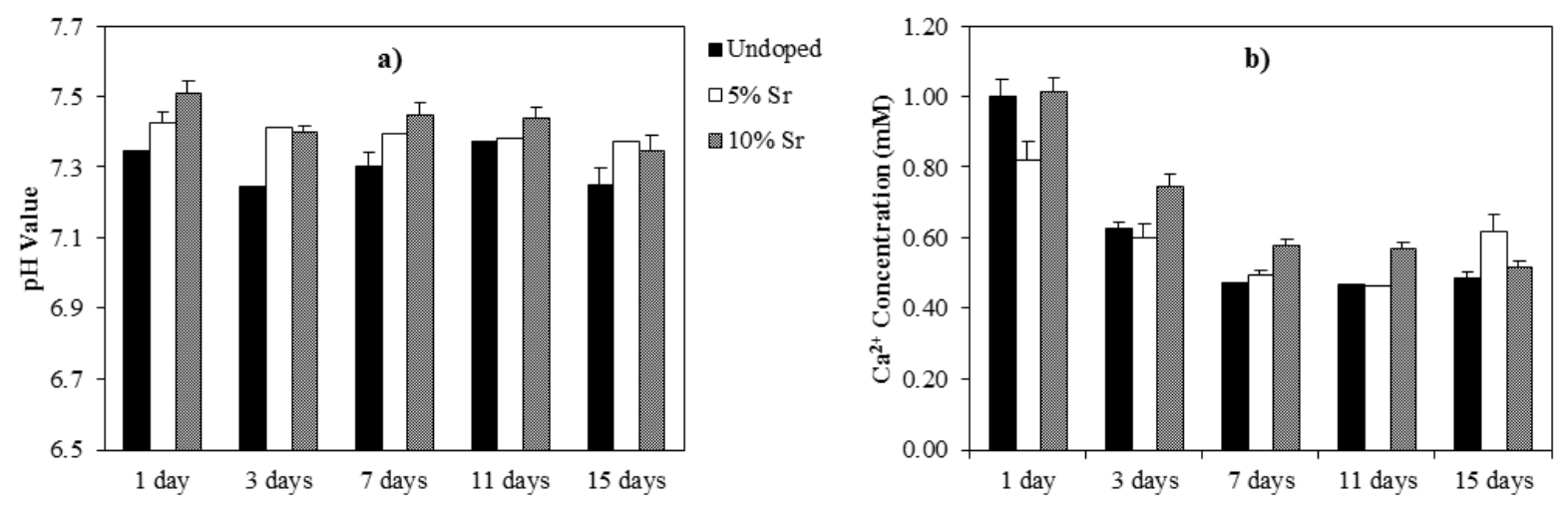

- Undoped $\square 5 \% \mathrm{Sr}$ $10 \% \mathrm{Sr}$
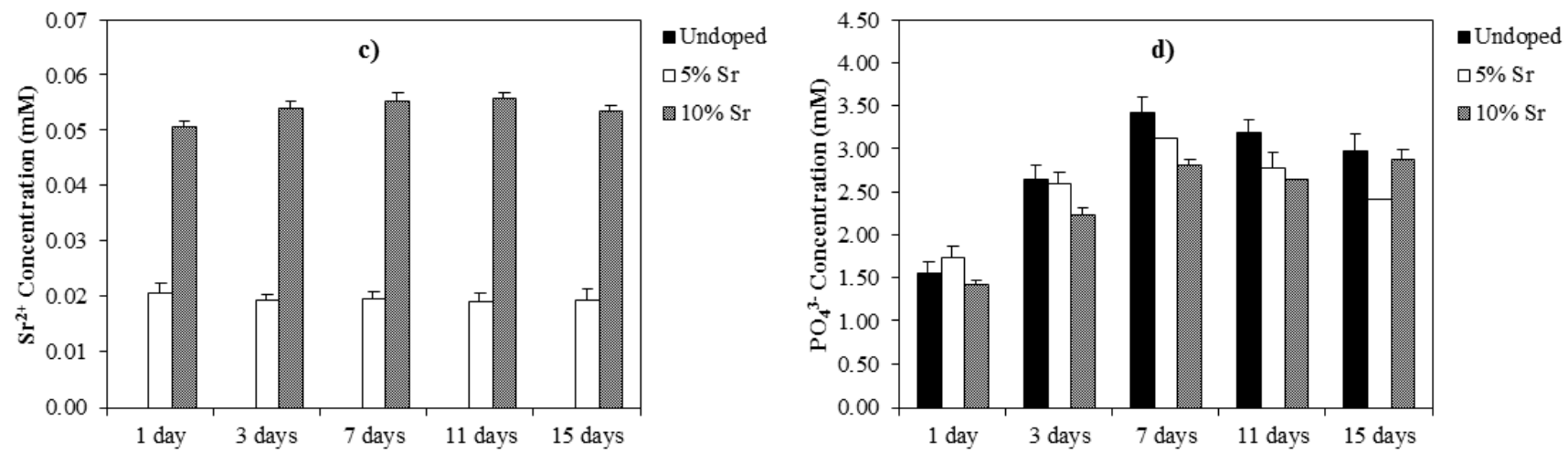

Figure 7. The a) $\mathrm{pH}$ and concentrations of b) $\mathrm{Ca}^{2+}$, c) $\mathrm{Sr}^{2+}$, and d) $\mathrm{PO}_{4}{ }^{3-}$ in culture media during MC3T3-E1 viability experiments on cements prepared with undoped, $5 \% \mathrm{Sr}$, and $10 \% \mathrm{Sr}$ containing DCPD, i.e. 5\%SrDCPD and 10\%SrDCPD. 

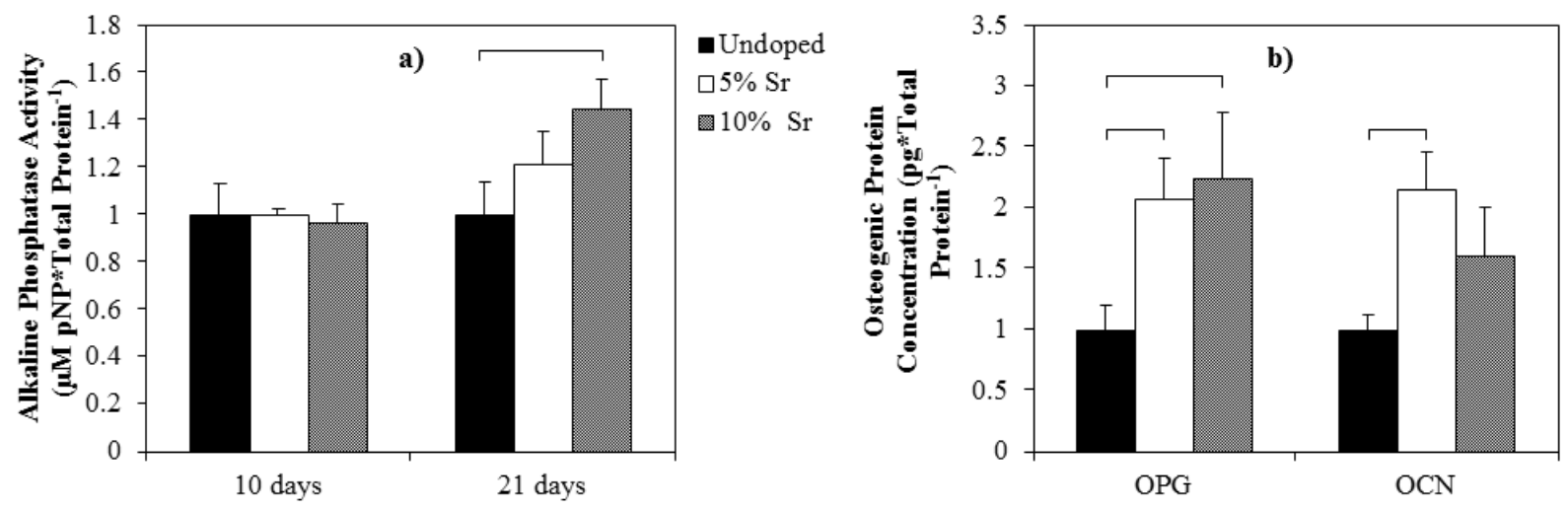

-Undoped $\square 5 \% \mathrm{Sr}$ $\square 10 \% \mathrm{Sr}$
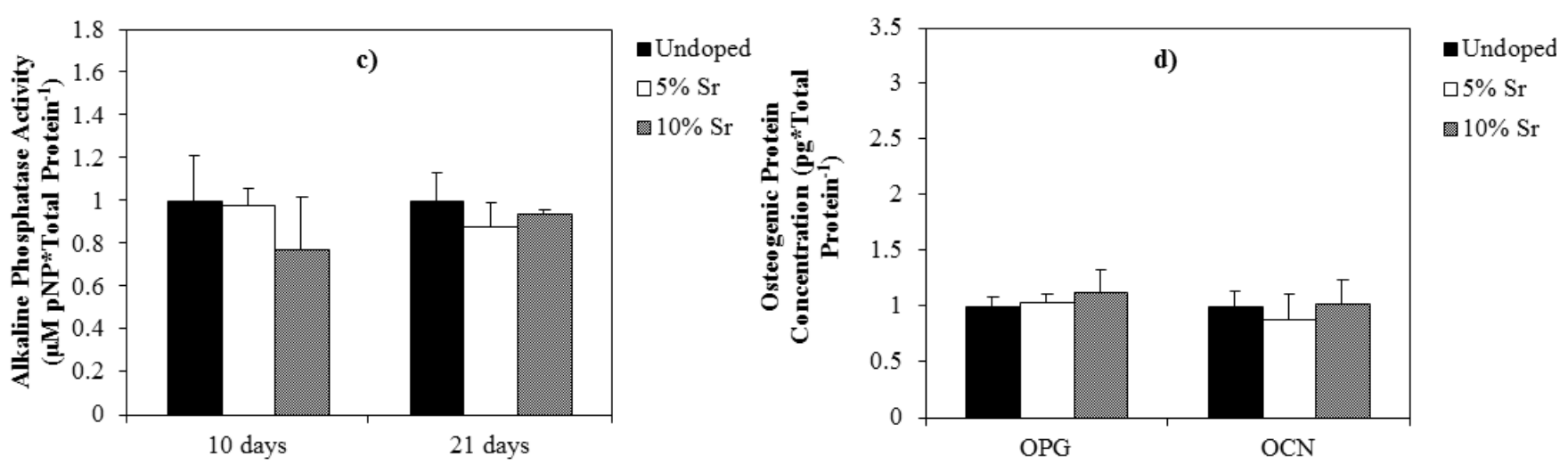

Figure 8. Alkaline phosphatase activity after 10 and 21 days and osteogenic protein expression after 21 days of MC3T3-E1 cells cultured a)-b) directly on cement scaffolds and c)-d) indirectly with cement scaffolds in osteogenic media. Four repeats were performed for each condition. A p value of $<0.05$ was considered significant. 


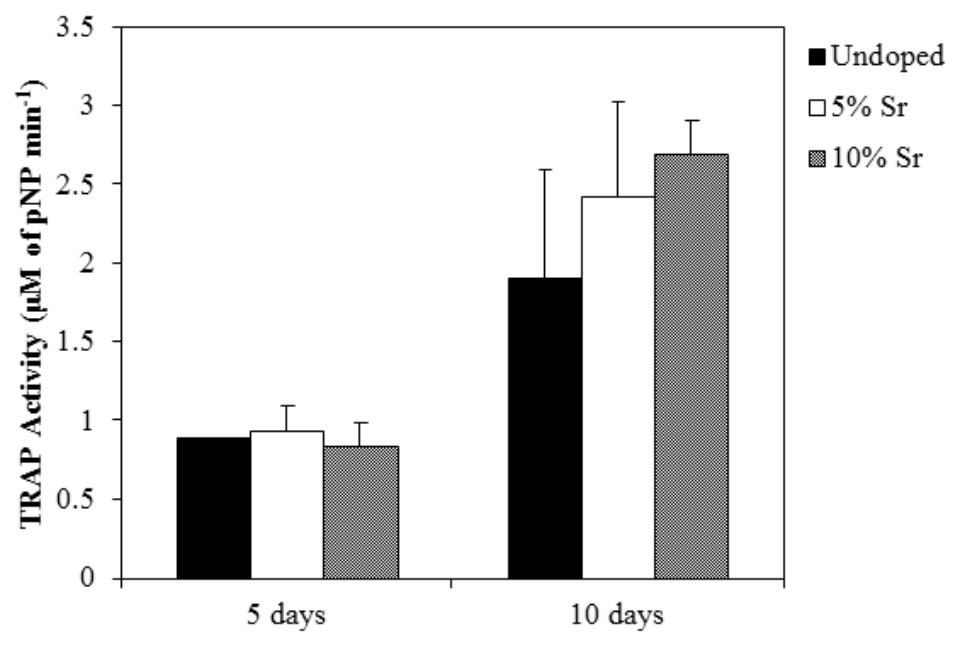

Figure 9. Tartarate resistant acidic phosphatase (TRAP) activity of RAW 264.7 cells cultured directly on cement scaffolds in media supplemented with $50 \mathrm{ng}^{*} \mathrm{~mL}^{-1}$ of RANKL. Four repeats were performed for each condition. A $p$ value of $<0.05$ was considered significant. 
a)
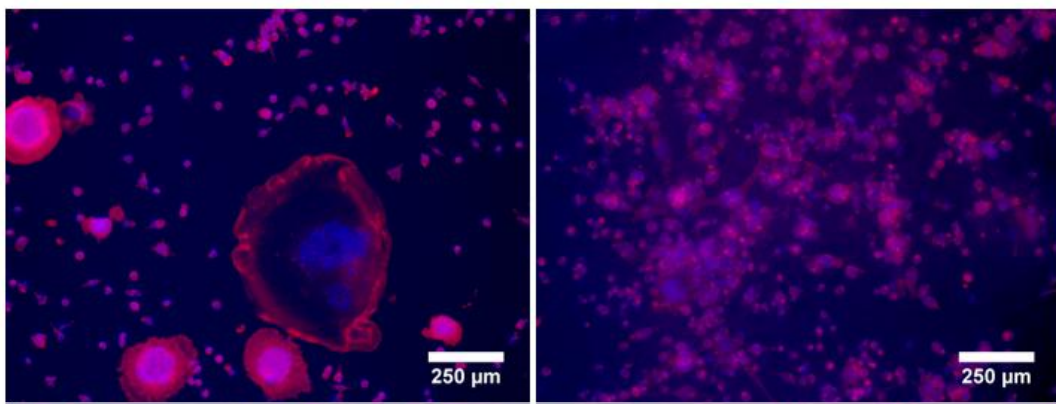

b)

c)
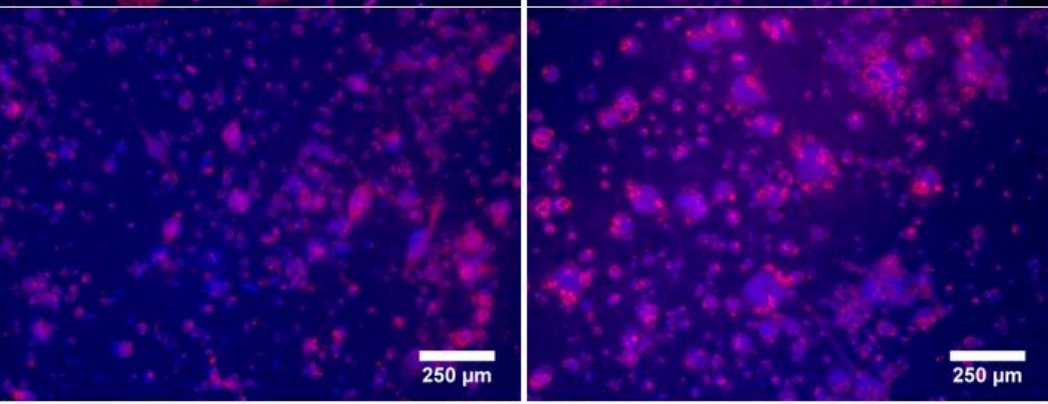

d)

Figure 10. Cytoskeletal staining of RAW 264.7 cells cultured a) on culture plastic, and directly on cement scaffolds prepared with b) undoped DCPD, c) 5\% Sr containing DCPD, 5\% SrDCPD, and d) $10 \%$ Sr containing DCPD, 10\% SrDCPD in media supplemented with $50 \mathrm{ng} \mathrm{mL}^{-1}$ of RANKL for 10 days. 


\section{Sr-DCPD + TTCP $\Longrightarrow$ Sr-HA Cement}
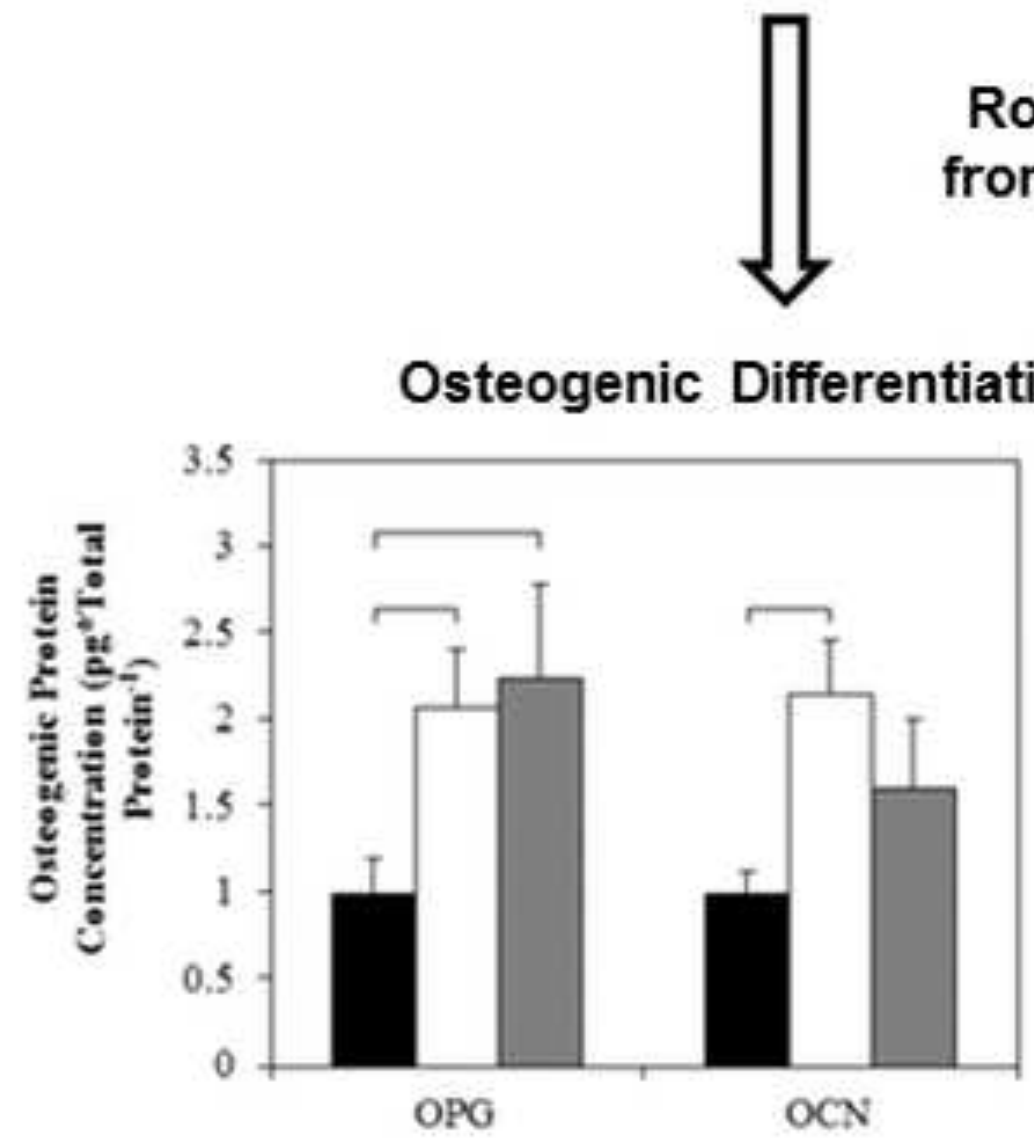

Role of $\mathrm{Sr}^{2+}$ Release from Cement Scaffold

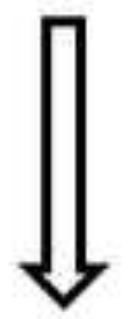

Osteoclastic Differentiation

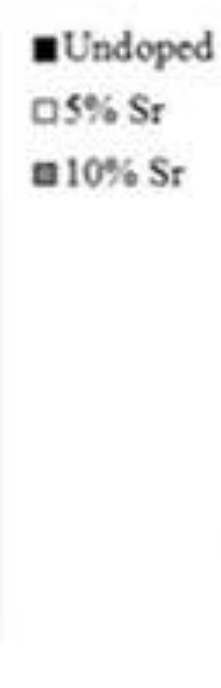

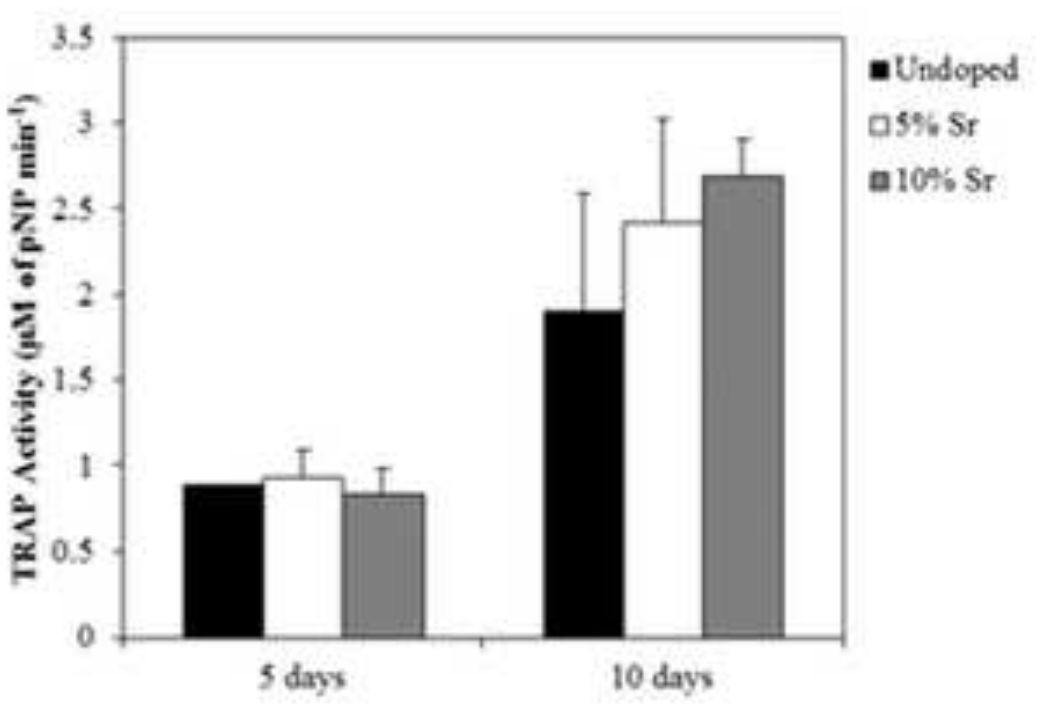

